\title{
Retinoic Acid Is Required for Oligodendrocyte Precursor Cell Production and Differentiation in the Postnatal Mouse Corpus Callosum
}

\author{
Vivianne E. Morrison, ${ }^{1,2}$ Victoria N. Smith, ${ }^{1}$ and ${ }^{1}$ Jeffrey K. Huang ${ }^{1,2}$ \\ https://doi.org/10.1523/ENEURO.0270-19.2019 \\ ${ }^{1}$ Department of Biology and Center for Cell Reprogramming, Georgetown University, Washington, DC 20057 and \\ ${ }^{2}$ Interdisciplinary Program in Neuroscience, Georgetown University, Washington, DC 20057
}

\begin{abstract}
Myelination of the CNS relies on the production and differentiation of oligodendrocyte (OL) precursor cells (OPCs) into mature OLs. During the first month of postnatal life, OPCs that populate the corpus callosum (CC) arise from neural stem cells (NSCs) in the subcallosal subventricular zone (SVZ), and then differentiate to generate myelinating OLs. However, the signals that regulate these processes are not fully understood. In this study, we show that endogenous expression of the retinoic acid (RA)-synthesizing enzyme retinaldehyde dehydrogenase 2 (RALDH2) is required for OPC generation and differentiation in the postnatal subcortical white matter. In male and female pups, conditional deletion of Raldh2 reduced OPC numbers and differentiation. Moreover, decreased OPC numbers coincided with reductions in NSC survival and expression of the sonic hedgehog (SHH) signaling effector protein Gli1 in the SVZ. Additionally, GFAP expression in the CC was decreased, and cortical neuron numbers were altered. Our work suggests a role for endogenous RALDH2-dependent RA synthesis in OPC production and differentiation in the CC, as well as in the development of other cell types derived from NSCs in the embryonic ventricular zone (VZ) and SVZ, as well as the postnatal subcallosal SVZ.
\end{abstract}

Key words: meninges; oligodendrocyte precursor cells; oligodendrocytes; postnatal; retinoic acid; subcortical white matter

\section{Significance Statement}

Postnatal forebrain myelination requires the production of oligodendrocytes (OLs), but the signals ensuring normal numbers of OLs have not been fully described. We demonstrate that loss of the retinoic acid (RA)-synthesizing enzyme retinaldehyde dehydrogenase 2 (RALDH2) decreased the number and differentiation of OL precursor cells (OPCs), leading to a deficit in OLs. These reductions co-occurred with increased death of neural stem cells (NSCs), reduced expression a sonic hedgehog (SHH) pathway effector, and altered development of NSC-derived neurons and white matter astrocytes. Our results suggest that endogenous RA synthesis is required for the development of NSC-derived forebrain cells.

\section{Introduction}

In the CNS, oligodendrocytes (OLs) promote neuronal survival (Wilkins et al., 2003; Chang et al., 2016), regulate neuronal energy metabolism (Saab et al., 2013), and influence neurotransmission through myelination (Nave,

Received July 11, 2019; accepted December 7, 2019; First published December 26, 2019.

The authors declare no competing financial interests.
2010). In the postnatal corpus callosum (CC), $>80 \%$ of OLs arise from differentiating dorsally derived OL precursor cells (OPCs), which are characterized in part by their expression of the proteoglycan neural/glial antigen 2 (NG2) and arise from neural stem cells (NSCs) in the

Author contributions: V.E.M. and J.K.H. designed research; V.E.M. and V.N.S. performed research; V.E.M. and J.K.H. analyzed data; V.E.M. and J.K.H. wrote the paper. 
subcallosal subventricular zone (SVZ). This process depends on sonic hedgehog (SHH) signaling in NSCs (Richardson et al., 2006; Winkler et al., 2018). Given the role of OLs in postnatal brain function and devastating effects of demyelination (Steenweg et al., 2010; Stangel, 2012), it is important to identify signals that support OPC production and differentiation.

One candidate is retinoic acid (RA), a highly conserved morphogen synthesized from dietary vitamin A. Vitamin A (also called retinol) undergoes two oxidative steps, the second of which is mediated by retinaldehyde dehydrogenases (RALDH; Napoli, 2012). RA binds to nuclear RA receptor (RAR)-retinoid $X$ receptor ( $R X R)$ heterodimers at RA response elements (RAREs) and modifies chromatin to regulate gene transcription (Paschaki et al., 2013). In this way, RA influences fundamental processes in CNS cells, such as proliferation, survival, differentiation, and maturation (Maden, 2002; Gudas, 2012).

Early studies suggested a link between vitamin A deficiency and myelination in vivo (Clausen, 1969; Kean, 1970; Bhat and Rao, 1978). Later, in vitro studies found that exogenous RA influences OPC differentiation (Barres et al., 1994; Laeng et al., 1994; Noll and Miller, 1994). Moreover, it was found that RA signaling supports OPC differentiation and remyelination following spinal cord injury, and expression of RALDH2 in $\mathrm{NG}^{+}$cells was necessary for this effect (Huang et al., 2011; Goncalves et al., 2019). Critically, in the embryonic forebrain of Raldh2 null mice, transcription factors and signaling pathways known to promote OPC production (i.e., OLIG2 and SHH, respectively) were reduced (Ribes et al., 2006; Emery, 2010; Tong et al., 2015), raising the possibility of a role for RALDH2-dependent endogenous RA synthesis in OL development. However, since Raldh2 null mice die in utero, whether this occurrs in vivo remained unknown.

RALDH2 expression patterns in the postnatal brain are not fully understood. It is well accepted that RALDH2 is expressed in the meninges (Smith et al., 2001; Wagner et al., 2002; Siegenthaler et al., 2009; Haushalter et al., 2017), and it is likely that cells in the parenchymal neurovascular niche express RALDH2, but the exact identity of $\mathrm{RALDH}^{+}$cells is unclear: some report co-localization with NG2 (Mey et al., 2005; Kern et al., 2007) while others

This work was supported by the National Science Foundation Graduate Research Fellowship Program Award DGE-0903443 Internal Grant Number RX2700 403 (to V.E.M.), the National Multiple Sclerosis Society Research Grant G-1508-05906, and the Harry Weaver Neuroscience Award JF-180631381 (to J.K.H.)

Acknowledgements: We thank Dr. Wojciech Krezel and Dr. Pascal Dollé (IGBMC, Strasbourg, France) for the Raldh2L2/L2 30 mouse line, members of the Huang laboratory for comments on this project, and Dr. Bruce Carter at Vanderbilt University for allowing V.E.M. to conduct part of her Georgetown University doctoral research remotely from his laboratory.

V. E. Morrison's present address: Vanderbilt University, 2215 Garland Avenue, 625 Light Hall, Nashville, TN 37232.

Correspondence should be addressed to Jeffrey K. Huang at jeffrey.huang@georgetown.edu.

https://doi.org/10.1523/ENEURO.0270-19.2019

Copyright (C) 2020 Morrison et al.

This is an open-access article distributed under the terms of the Creative Commons Attribution 4.0 International license, which permits unrestricted use, distribution and reproduction in any medium provided that the original work is properly attributed. find $\mathrm{Ng} 2$ and Raldh2 to be largely mutually exclusive and expressed in different perivascular cell populations: $\mathrm{Ng} 2$ in mural cells [pericytes and smooth muscle cells (SMCs)] and RALDH2 in a subset of perivascular cells with fibroblast-like properties (FB cells), characterized by expression of collagen, type 1, $\alpha 1$ (Col1a1; Kelly et al., 2016; Vanlandewijck et al., 2018). However, both of these studies show that, irrespective of NG2 status, cells expressing RALDH2 are positive for platelet-derived growth factor receptor $\beta$ [PDGFR $\beta$; in addition to consulting the protein expression data from Kelly et al. (2016), the online gene expression database generated by Vanlandewijck et al. (2018), was used to make this determination]. Finally, RALDH2 has been observed to co-localize with mature OL markers like RIP and CNPase in the adult spinal cord (Mey et al., 2005), showing that OLs derived from NG2 ${ }^{+}$ OPCs express RALDH2 in the CNS.

To determine whether endogenous RA synthesis impacts postnatal OL development, we conditionally deleted Raldh2 in the CNS from cells that express or have expressed NG2 at some point in their lineage. We found that the numbers of OPCs and OLs in the postnatal CC were reduced in the Raldh2 cKO, and the deficit in OL lineage cells was accompanied by increased NSC death and reduced expression of a downstream effector of the $\mathrm{SHH}$ pathway in the subcallosal SVZ. Additionally, we observed altered development of callosal astrocytes and cortical neurons in cKO mice. Our results suggest that endogenous RALDH2-dependent RA synthesis regulates the generation of multiple forebrain cell types and the maturation of OL lineage cells.

\section{Materials and Methods}

\section{Experimental design and statistical analysis}

Comparisons were made between $\mathrm{Ng} 2-\mathrm{Cre}:$ Raldh2 $2^{\text {floxflox }}$ mice and Raldh2 $2^{\text {flox/flox }}$ control littermates. In some cases, comparisons were made between time points within genotypes. Males and females were equally represented in the analyses. Tissue samples were collected as litters became available over a period of several months. The experimenter was blinded to the genotypes and time points until all the raw values (i.e., cell number, puncta number, and area) were recorded in Excel. For each experiment, there were at least three mice per genotype per time point. For each mouse in an experiment, nine images were analyzed (three images per brain section, three brain sections per slide). Each experiment was independently repeated at least twice using different animals for each round. Data from multiple independent experiments were collated after ensuring that variations in the means were not due to inter-experiment variation through a MANOVA. GraphPad Prism version 8 (RRID: SCR_002798) was used to perform all statistical analyses, including one-tailed and two-tailed unpaired $t$ tests, oneway ANOVAs with Sidak's test for multiple comparisons, and Shapiro-Wilk normality tests. Exact $p$ values are reported when possible, but when not supplied by Prism the following notations are used to indicate the significance: $* p<0.05, * * p<0.01, * * * p<0.001, * * * * p<0.0001$. All comparisons made in this work are included in a statisti- 


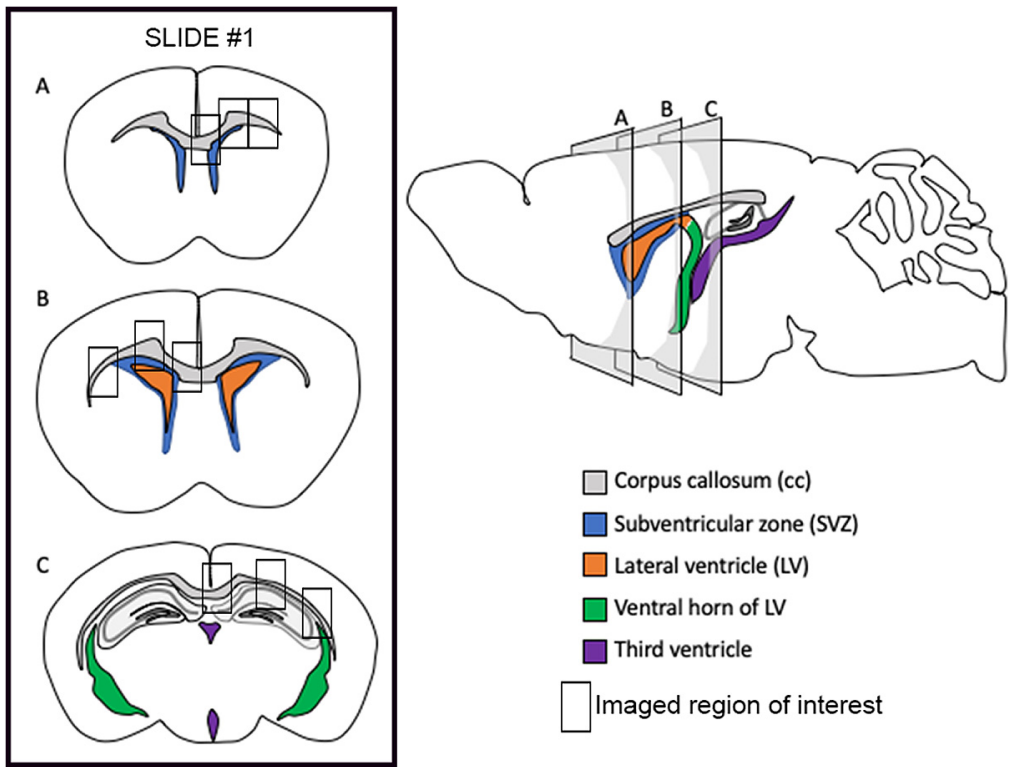

Figure 1. Illustration of sample collection and sectioning. Representative slide with three coronal sections (left, sections $\boldsymbol{A}-\boldsymbol{C}$ ) that correspond to three regions along the rostral-caudal axis depicted on the sagittal diagram of the mouse brain (right, regions $\boldsymbol{A}-\boldsymbol{C}$ ). $\mathbf{A}$ color-coded key indicates which structures on the coronal and sagittal sections are corresponding. The slide on the left also shows three small boxes on each section that correspond to regions imaged and used for analysis. Right and left sides were counterbalanced as shown.

cal summary (Table 1), indicating the groups and time points compared, the data distribution, the test used, and the confidence intervals.

\section{Animals}

Mice of both sexes from the following strains were used: the B6;FVB-Ifi208Tg(Cspg4-cre)1Akik/J line (RRID: IMSR_JAX:008533; Zhu et al., 2008) and the floxed Raldh2 line (Raldh2 ${ }^{\mathrm{L} 2 / \mathrm{L} 2}$, here written as Raldh2 ${ }^{\mathrm{fl} / \mathrm{fl}}$; Vermot et al., 2006). The Raldh2 ${ }^{\mathrm{L} 2 / \mathrm{L} 2}$ line was generously provided by Dr. Wojciech Krezel and Dr. Pascal Dollé (IGBMC, Strasbourg, France). Mice were maintained on a 12/12 h light/dark cycle with food and water ad libitum. All experiments were performed in accordance with approved Institutional Animal Care and Use Committee (IACUC) protocols of Georgetown University.

\section{Genotyping primers}

Primers were synthesized by Eurofins Genomics, Inc. (https://www.eurofinsgenomics.com/en/products/ dnarna-synthesis/all-oligo-options/). Primer sequences: NG2-Cre, product size: $100 \mathrm{bp}, \mathrm{Tm}: 55^{\circ} \mathrm{C}$; forward: GCGGTCTGGCAGTAAAAACTATC; reverse: GTGAAACAGCATTGCTGTCACTT; control (IL-2), product size: 324 bp, Tm: $55^{\circ} \mathrm{C}$; forward: CTAGGCCACAGAATTGAAAGATCT; reverse: GTAGGTGGAAATTCTAGCATCATCC; RALDH2 $2^{\mathrm{fl} / \mathrm{fl}}$, product size: WT, $150 \mathrm{bp}$; L2: $250 \mathrm{bp}, \mathrm{Tm}: 61^{\circ} \mathrm{C}$; forward: CCCTCCGCTTGTCAAACCACCTTCTGCTATATT; reverse: GGCAGCTGTGGAGAACATITATATCCATGTTG.

\section{Sample collection and processing}

Full litters were collected at postnatal day (P)2, P7, P14, $\mathrm{P} 21$, and $\mathrm{P} 120$. Animals were killed with isoflurane before cervical dislocation and decapitation. The brain was ex- tracted, embedded in OCT, and flash-frozen in ice-cold isopentane, then stored at $-80^{\circ} \mathrm{C}$.

\section{Sectioning}

The whole-brain samples embedded in OCT were left for $1 \mathrm{~h}$ in the cryostat $\left(-20^{\circ} \mathrm{C}\right)$ to soften before cryosectioning. The collection of $10-\mu \mathrm{m}$-thick sections began when the hypercellular region of the SVZ appeared under the anterior forceps of the CC. Thirty slides labeled \#1 through $\# 30$, each bearing three sections corresponding to different points along the rostral-caudal axis (Fig. 1), were collected for each animal and the remaining OCTembedded brain was returned to $-80^{\circ} \mathrm{C}$. The sections were stored at $-80^{\circ} \mathrm{C}$ until use.

\section{Immunofluorescence}

Slides were removed from the $-80^{\circ} \mathrm{C}$ freezer and immediately fixed in $4 \%$ paraformaldehyde (PFA) for $30 \mathrm{~min}$ at room temperature. Slides were washed twice in $1 \times$ Tris-buffered saline (TBS) for 5 min, permeabilized for 2 min in 1\% Triton X-100 in 1× TBS and blocked with $10 \%$ donkey serum (Sigma-Aldrich D9663), 0.25\% Tween in $1 \times$ TBS for 30 min at room temperature. Primary antibodies were diluted in $1 \times$ TBS (see below for dilution factors) and incubated overnight at $4^{\circ} \mathrm{C}$. Slides were washed twice for $3 \mathrm{~min}$ in $0.05 \%$ Tween in $1 \times$ TBS before incubation at room temperature in the dark for $1 \mathrm{~h}$ with the secondary antibody diluted 1:1000 in 1× TBS. Slides were washed twice for $3 \mathrm{~min}$ in $0.05 \%$ Tween in $1 \times$ TBS in an opaque slide rack. ProLong Gold Antifade mounting media with DAPI was applied before placing a coverslip over the sections. Slides dried overnight at room temperature in the dark before imaging. Negative controls receiv- 
ing only the secondary antibody accompanied each experiment.

\section{Antibodies}

Ms: Mouse; Rb: Rabbit; Gt: Goat.

\section{Primary}

Ms-Olig2: Millipore MABN50, clone 211F1.1, 1:100 (RRID:AB_10807410). Rb-Olig2: Millipore AB9610, 1:500 (RRID:AB_570666). Rb-Ki67: ThermoFisher, PA5-19462, 1:200 (RRID:AB_10981523). Ms-CC1: Millipore Sigma, OP80, 1:100 (RRID:AB_2057371). Gt-PDGFR $\alpha$ : R\&D Systems AF1062, $25 \mu \mathrm{g}, 1: 200 ; 100 \mu \mathrm{g}, 1: 60$ (RRID: AB_2236897). Gt-PLP: Santa Cruz Biotechnology, G-17, sc-23570 (discontinued), 1:250 (RRID:AB_2165797). RbNF200: Sigma-Aldrich N4142, 1:250 (RRID:AB_477272). Ms-Nestin: Millipore Sigma, clone rat-401, MAB353, 1:500 (RRID:AB_94911). Gt-PDGFR $\beta$ : R\&D Systems AF1042, 1:200 (RRID:AB_2162633). Rb-Laminin: Millipore AB2034, 1:100 (RRID:AB_91209). Rb-NG2: Millipore AB5320, 1:200 RRID:AB_91789). Rb-ALDH1A2: Abcam AB75674, 1:200 (RRID:AB_10676130). Rb-IBA1: Wako Chemicals 019-19741, 1:750 (RRID:AB_839504). RbGFAP: Millipore AB5804, 1:500 (RRID:AB_2109645). RtCTIP2: Abcam AB18465, 1:500 (RRID:AB_2064130). RbTBR1: Abcam AB31940, 1:50 (RRID:AB_2200219). MsSATB2: Abcam AB515102, 1:500 (RRID:AB_882455).

\section{Secondary}

All Alexa Fluor secondaries were raised in donkey and were purchased from ThermoFisher Scientific [anti-mouse 488, R37114 (RRID:AB 2556542); anti-rabbit 488, R37118 (RRID: AB_2556546); anti-goat 488, A-11055 (RRID:AB_2534102); (anti-mouse 594, R37115 (RRID:AB_2556543); anti-rabbit 594 R37119 (RRID:AB_2556547); anti-goat 594, A-11058 (RRID:AB_2534105); and (anti-rabbit 647, A-31573 (RRID: AB_2536183)].

\section{Nuclear stain and mounting medium \\ ProLong Gold Antifade reagent with DAPI (Invitrogen, P36941).}

\section{In situ hybridization, RNAscope assay}

Reagents were purchased online from Advanced Cell Diagnostics. Slides were removed from the $-80^{\circ} \mathrm{C}$ freezer and immediately fixed in $4 \%$ PFA for $15 \mathrm{~min}$ at room temperature. Slides were dehydrated through a series of incubations in ethanol at room temperature then subjected to a pretreatment step with the kit's protease IV and incubated for $30 \mathrm{~min}$ at room temperature. Slides were rinsed twice with $1 \times$ PBS. The RNAscope assay was performed exactly as described by the manufacturer. Amplification-4C was used for the final step.

\section{Probes}

Raldh2: Mm-Aldh1a2-O1 targeting base pairs 821-2201 of NM_009022.4, catalog \#540221-C3. Olig2: Mm-Olig2-C2, catalog \#447091-C2. Gli1: Mm-Gli1-C1, catalog \#311001-C1

\section{Accessory reagents}

Protease III and IV catalog \#322340; Multiplex Detection Reagents catalog \#320851; Wash Buffer Reagents catalog \#310091.

\section{Terminal deoxynucleotidyl transferase (TdT) dUTP Nick-end labeling (TUNEL) assay}

Slides were dried at room temperature for $15 \mathrm{~min}$, fixed in $4 \%$ PFA for $30 \mathrm{~min}$ at room temperature, then washed twice in $1 \times$ TBS for $3 \mathrm{~min}$. Slides were then subjected to the TUNEL assay manufactured by Sigma-Aldrich (Roche, catalog \#11684795910) exactly as specified in the manufacturer's instructions. A positive control slide was treated with DNase I (Sigma-Aldrich D5025; $1 \mathrm{U} / 10 \mu \mathrm{l}$ of DNase I buffer, $20 \mathrm{mM}$ Tris- $\mathrm{HCl}, 2 \mathrm{mM} \mathrm{MgCl}$, and $50 \mathrm{mM}$ $\mathrm{KCl}$; $\mathrm{pH}$ 8.4) before application of the TUNEL reaction mixture; a negative control slide received the labeling solution instead of the TUNEL reaction mixture. Slides were then rinsed three times with $1 \times$ TBS and mounted with ProLong Gold Antifade reagent with DAPI. Slides were left overnight at room temperature in the dark to dry until imaging.

\section{Imaging and quantification \\ Immunofluorescence}

To ensure that similar regions along the rostral-caudal axis were compared between control and cKO mice, only slides with corresponding numbers were included in a given experiment. For example, in the first experiment, only slide \#1 of each animal included in the experiment would be used. When counting cells was not an appropriate measure, we measured the area stained positive for a given marker. To do this, the image was thresholded in Fiji (RRID:SCR_002285; shift + T; left drop down menu: "default"; right drop down menu: "red background"; check "dark background", adjust slider appropriately so that the red area corresponds to what is judged as positive staining), then the area of the thresholded region was measured ("analyze" tab > set measurements > check "area" and "limit to threshold"; click M). In all cases, to facilitate the analysis, the "polygon selection" tool was used to isolate the CC and the region outside the CC was removed ("edit" tab > clear outside). Cortical thickness was determined using the "straight line" tool in Fiji on DAPI-stained cortical sections imaged with a $4 \times$ objective. A line was drawn from the meninges to the bottom of layer 6 and the beginning of the CC, and the length was measured (push " $M$ " and the length will appear in a new pop-up window). The ending point was chosen based on cell density (higher in the layer 6 and lower in the CC) as well as the orientation of cells in the CC (subcallosal white matter cells orient themselves along the axonal tracts coursing across the midline, creating patterns resembling a beaded necklace that is perpendicular to the radial organization of the cortical layers).

\section{RNAscope}

In RNAscope, fluorescent puncta with diameters of 0.5 $\mu \mathrm{m}$ correspond to single transcripts, while puncta with larger diameters correspond to clusters of transcripts. For Raldh2 and Gli1 puncta, the Imaris imaging platform (RRID:SCR_007370) was used to count the number of puncta with diameters ranging from 0.5 to $0.9 \mu \mathrm{m}$. Before puncta quantification in Imaris, the images were processed in Fiji. For quantification of Gli1 puncta, the channel containing Gli1 staining was masked so that only DAPI 
was visible. The freehand selection tool was used to trace around the entirety of the SVZ present in the image. The area of the SVZ was recorded in Excel, and the image was cropped, leaving only the SVZ visible. For Raldh2 puncta, the channel containing Raldh2 staining was masked, and DAPI staining was used to isolate the midline meninges and the image was cropped. The images of the isolated SVZs and midline meninges were then analyzed using Imaris. Briefly, one image from a given experiment was chosen at random from which to build a dot detection protocol that would then be run in batch and applied to all the images. The settings used to build a dot detection protocol were specific to the probe being used, i.e., the Gli1 dot detection protocol was different from that used for Raldh2 owing to differences in signal-to-noise ratios between the different probes.

\section{Imaging}

Imaging was done on a Nikon Eclipse Ti widefield fluorescence microscope using Nikon Plan Fluor 4X (NA: $0.13), 20 \times(N A: 0.5), 40 \times(O i l, N A: 1.3)$, or $100 \times(O i l, N A$ : 1.45) for immunofluorescence. An X-Cite 120 LED (Excelitas Technologies) was used.

\section{Results}

\section{RALDH2 expression in the postnatal mouse brain}

To observe in vivo the perivascular cell types relevant to endogenous RALDH2 expression and RA synthesis, we performed immunofluorescence analysis for NG2 and PDGFR $\beta$. NG2 is expressed by OPCs, mural cells (pericytes and SMCs), and some fibroblast-like perivascular cells, type 2 (FB2; Vanlandewijck et al., 2018). The latter two populations are characterized by co-staining with PDGFR $\beta$ while OPCs are PDGFR $\beta^{-}$. NG2 ${ }^{+}$PDGFR $\beta^{-}$ OPCs have small, round cell bodies and a halo of NG2 staining around them, the appearance of which is due to the extensive branching of OPC processes (Fig. 2A,B, arrowheads). $\mathrm{NG} 2{ }^{+} \mathrm{PDGFR} \beta^{+}$mural and FB2 cells are elongated in a pattern resembling blood vessels (Fig. $2 A, B$, co-staining indicated by white regions in $A$ as well as chevrons in $B$ ). Our staining also revealed $\mathrm{NG}^{-}$ PDGFR $\beta^{+}$cells that were elongated like mural and FB2 cells (Fig. $2 B$, thin arrow). This staining pattern likely identifies the FB populations, type 1 and some type 2 cells (FB1 and FB2, respectively; Vanlandewijck et al., 2018). The location of these different cells, based on our analysis of the immunofluorescence images presented here, is depicted in Figure 2C.

To characterize RALDH2 expression in the postnatal CNS, immunofluorescence analysis for RALDH2 in the brains of wildtype mice at P2 was performed with PDGFR $\beta$. We found that RALDH2 ${ }^{+}$cells co-localized with PDGFR $\beta^{+}$(Fig. 3B, right insets, arrowhead), but not all PDGFR $\beta^{+}$cells were RALDH2 ${ }^{+}$(Fig. $3 B$, right insets, chevron). Due to primary antibody incompatibilities, we were unable to perform RALDH2 co-staining with NG2 or Col1a1. Our results suggest that RALDH2 is expressed in PDGFR $\beta^{+}$cells in the meninges, along parenchymal blood vessels in the cortex and subcortical white matter, and choroid plexus stroma (Fig. 3B-E).
Since the meninges, choroid plexus, and vasculature are vulnerable to autofluorescence, we performed RNAscope in situ hybridization to confirm the location of Raldh2 expression in the CNS (Fig. 3G-l). We found that Raldh2 mRNA was only detectable in the meninges and in blood vessels immediately adjacent to the meninges (Fig. $3 H, l)$. We did not detect Raldh2 mRNA in other blood vessels deeper in the gray and white matter despite the presence of RALDH2 immunostaining in these structures. Raldh2 mRNA staining was most clearly visible in the midline meninges. This region is more frequently left intact after dissection of the brain from the skull, which can damage or unintentionally remove the dorsal meninges. Furthermore, this region is the closest meningeal tissue to regions relevant to OL lineage cell development such as the subcortical white matter and the subcallosal SVZ. We did not detect RALDH2 protein or mRNA in OPCs or other CNS cells at the time points analyzed. These results suggest that RALDH2 is mainly expressed in a subset of PDGFR $\beta^{+}$cells in the postnatal brain. Moreover, several studies have observed RALDH2 expression in NG2 + glia and mature OLs following spinal cord injury (Mey et al., 2005; Kern et al., 2007; Goncalves et al., 2018), thus implicating RALDH2-dependent RA synthesis in NG2 ${ }^{+}$ cells in OPC differentiation following injury. However, our examination of expression profiles databases generated by recent single cell RNA sequencing studies aimed at characterizing $\mathrm{OL}$ lineage cell progression and heterogeneity in the adult CNS revealed that Raldh2 was not expressed highly by any cell in the OL lineage (Marques et al., 2016, 2018). Nevertheless, all these findings suggest considerable overlap between RALDH2 and NG2 expression in the postnatal CNS and raise the possibility that in some cases OL lineage cells express RALDH2.

In light of this, we generated an Ng2-Cre:Raldh2 flox/flox mouse line, hereafter referred to as the Raldh2 cKO. We found that Raldh2 cKO mice were born normally and did not display any gross abnormalities. The absence of RALDH2 in PDGFR $\beta^{+}$cells in the meninges, choroid plexus stroma, and parenchymal blood vessels was confirmed in the Raldh2 cKO by immunofluorescence (Fig. $3 K-N)$. Moreover, RNAscope analysis revealed that the expression of Raldh2 in the midline meninges was decreased by $76 \%$ in cKO mice, consistent with the previously reported $80 \%$ efficacy of Cre recombinase in the $\mathrm{Ng} 2-\mathrm{Cre}$ line (Zhu et al., 2008; Fig. 30-R; $n$ is number of animals, $n=3$ controls, $n=4$ cKOs, unpaired $t$ test between genotypes at P2, one-tailed, $t_{(5)}=13.85, p<$ $0.0001^{\mathrm{a}}$ ). To determine whether Raldh2 cKO affected the number of blood vessels or PDGFR $\beta^{+}$cells, which could indirectly impact OL development, we performed immunofluorescence with PDGFR $\beta$ and the basal lamina marker Laminin to mark vasculature at $\mathrm{P} 14$, during peak OPC production and maturation (Fig. $4 A$ ). We show that the number of PDGFR $\beta^{+}$cells, the blood vessels, and blood vessel coverage by PDGFR $\beta^{+}$cells were not altered in the absence of RALDH2 (Fig. $4 B-F$, quantification of PDGFR $\beta^{+}$structures: $n$ is number of animals, $n=$ 5/genotype, unpaired $t$ test between genotypes at $\mathrm{P} 14$, two-tailed, $t_{(8)}=1.001, p=0.3463^{\mathrm{b}}$; quantification of 


\section{DAPI NG2 PDGFRb Co-labeled}

\section{A Control P2}
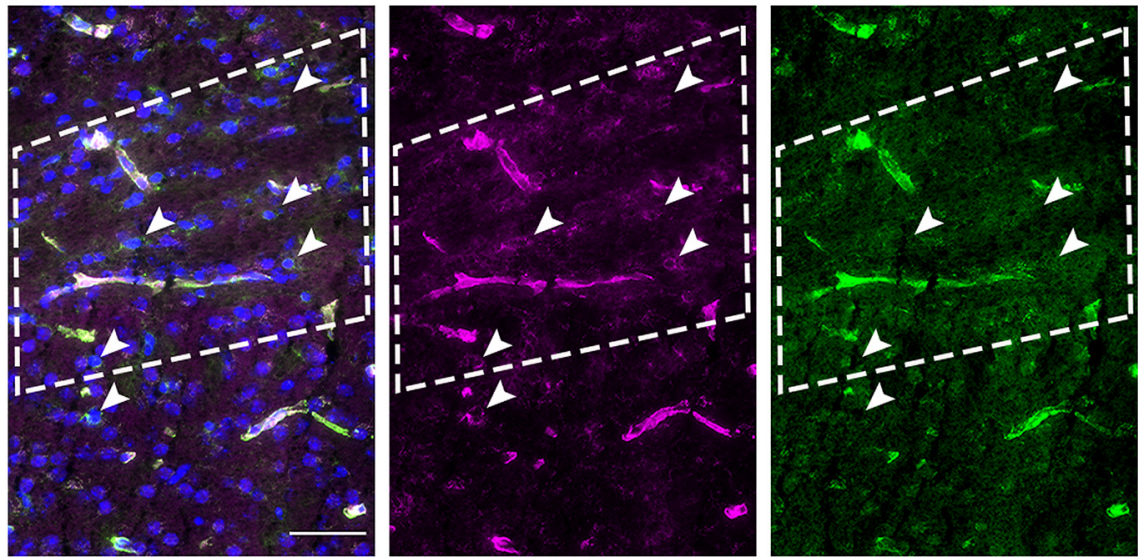

\section{DAPI NG2 PDGFRb Co-labeled}

\section{B Control P2}
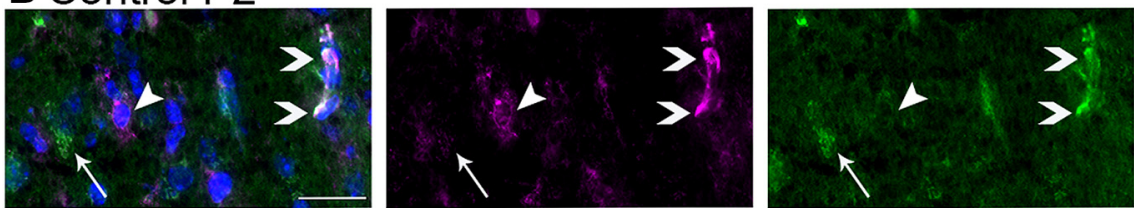

C

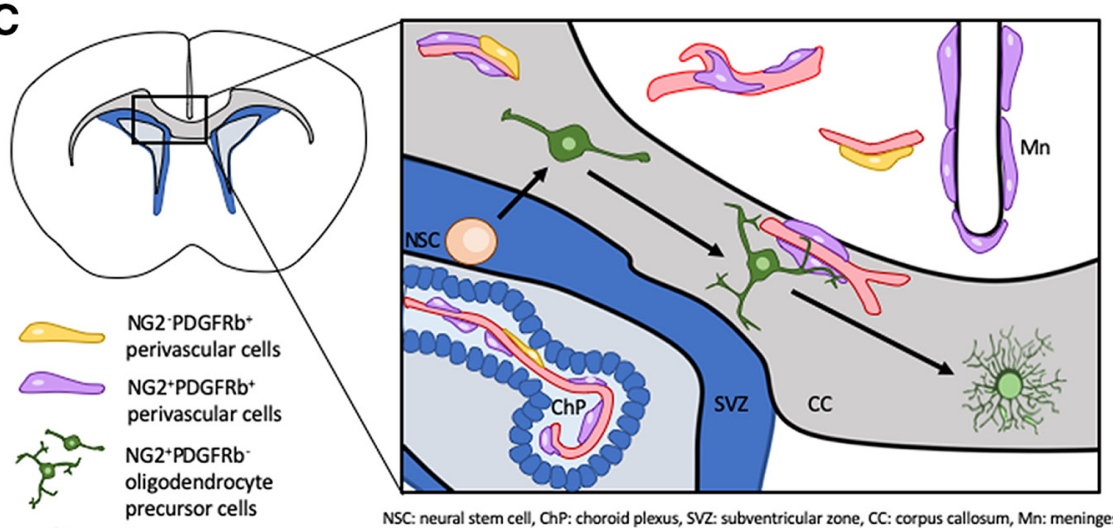

NG2-PDGFRb

oligodendrocytes

Figure 2. NG2 and PDGFR $\beta$ immunofluorescence identifies different perivascular cell populations and OPCs. $\boldsymbol{A}$, Immunofluorescence for NG2 (magenta) and PDGFR $\beta$ (green) in control CC (the area enclosed in the white dashed line) at P2. Co-localization in mural cells is seen in white. NG2 ${ }^{+}$PDGFR $\beta^{-}$cells are OPCs (arrowheads). $\boldsymbol{B}$, In addition to mural cells (white, chevrons) and OPCs (magenta, arrowhead), NG2 and PDGFR $\beta$ staining reveals NG2-PDGFR $\beta^{+}$cells (green, thin arrow). $\boldsymbol{C}$, Schematic illustrating the location of these three populations based on our observations. The three black arrows between the NSC and bipolar OPC, the bipolar and multipolar OPC, and the multipolar OPC and highly branched oligodendrocyte represent specification, maturation and differentiation, respectively, in the oligodendrocyte lineage. Scale bars: $50 \mu \mathrm{m}(\boldsymbol{A})$ and $25 \mu \mathrm{m}(\boldsymbol{B})$. Mn, meninges; CC, corpus callosum; ChP, choroid plexus; SVZ, subventricular zone; NSC, neural stem cell.

Laminin ${ }^{+}$structures: $n$ is number of animals, $n=5 /$ genotype, unpaired $t$ test between genotypes at P14, twotailed, $t_{(8)}=1.462, p=0.1820^{\circ}$; percentage of Laminin ${ }^{+}$ structures co-localizing with $\operatorname{PDGFR} \beta, n$ is number of animals, $n=5 /$ genotype, unpaired $t$ test between genotypes at P14, two-tailed, $t_{(8)}=1.784, p=0.1122^{d}$ ).

\section{Loss of RALDH2 reduces OPC and OL numbers}

To determine whether RA synthesis by Ng2-Crerecombined cells is required for normal OL development in vivo, we quantified the number of OL lineage cells, comprising OPCs and OLs, using the lineage marker OL transcription factor 2 (OLIG2; Zhou et al., 2000; Zhou and Anderson, 2002). OL lineage cells were analyzed in the $\mathrm{CC}$ at four time points that correspond to developmental OL lineage cell progression (P2, P7, P14, and P21). We observed significantly fewer OLIG2 ${ }^{+}$cells in cKO mice than controls at all time points examined (Fig. $5 B-D ; n$ is number of animals, $n=4-6 /$ genotype, one-way ANOVA with Sidak's test for multiple comparisons between geno- 

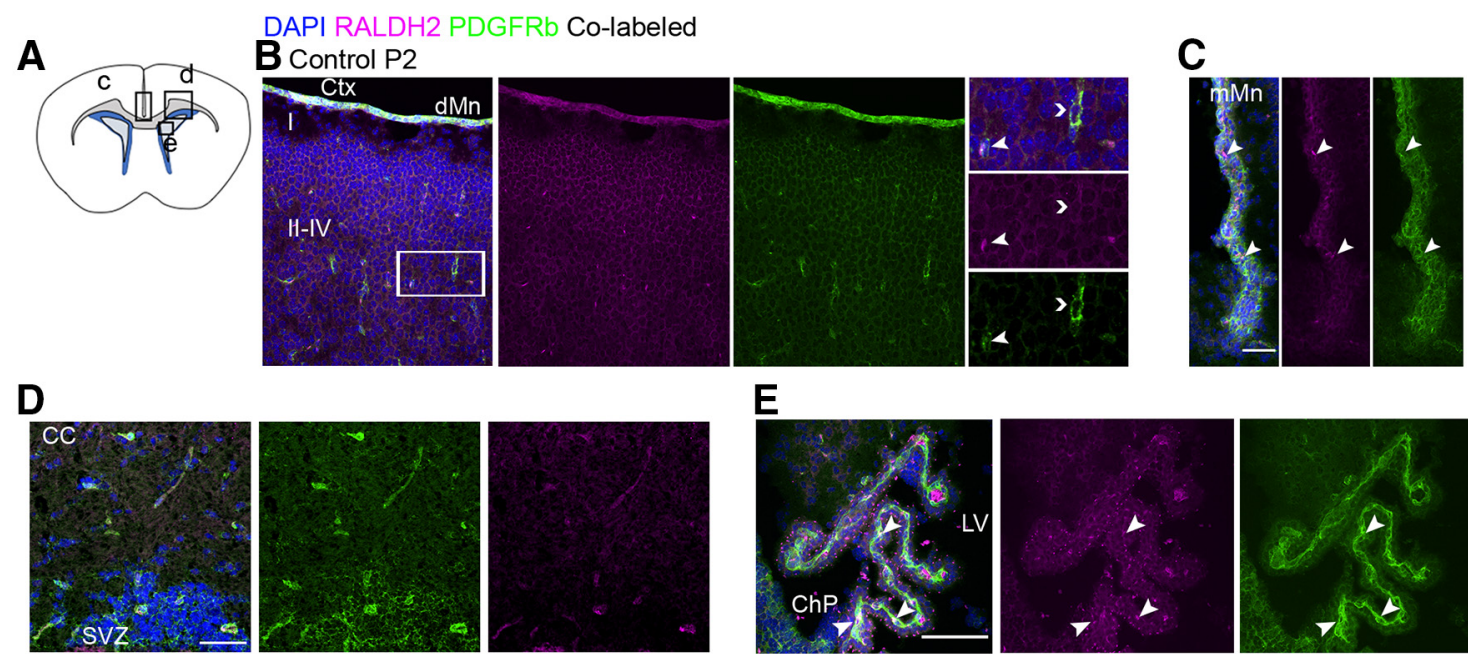

E
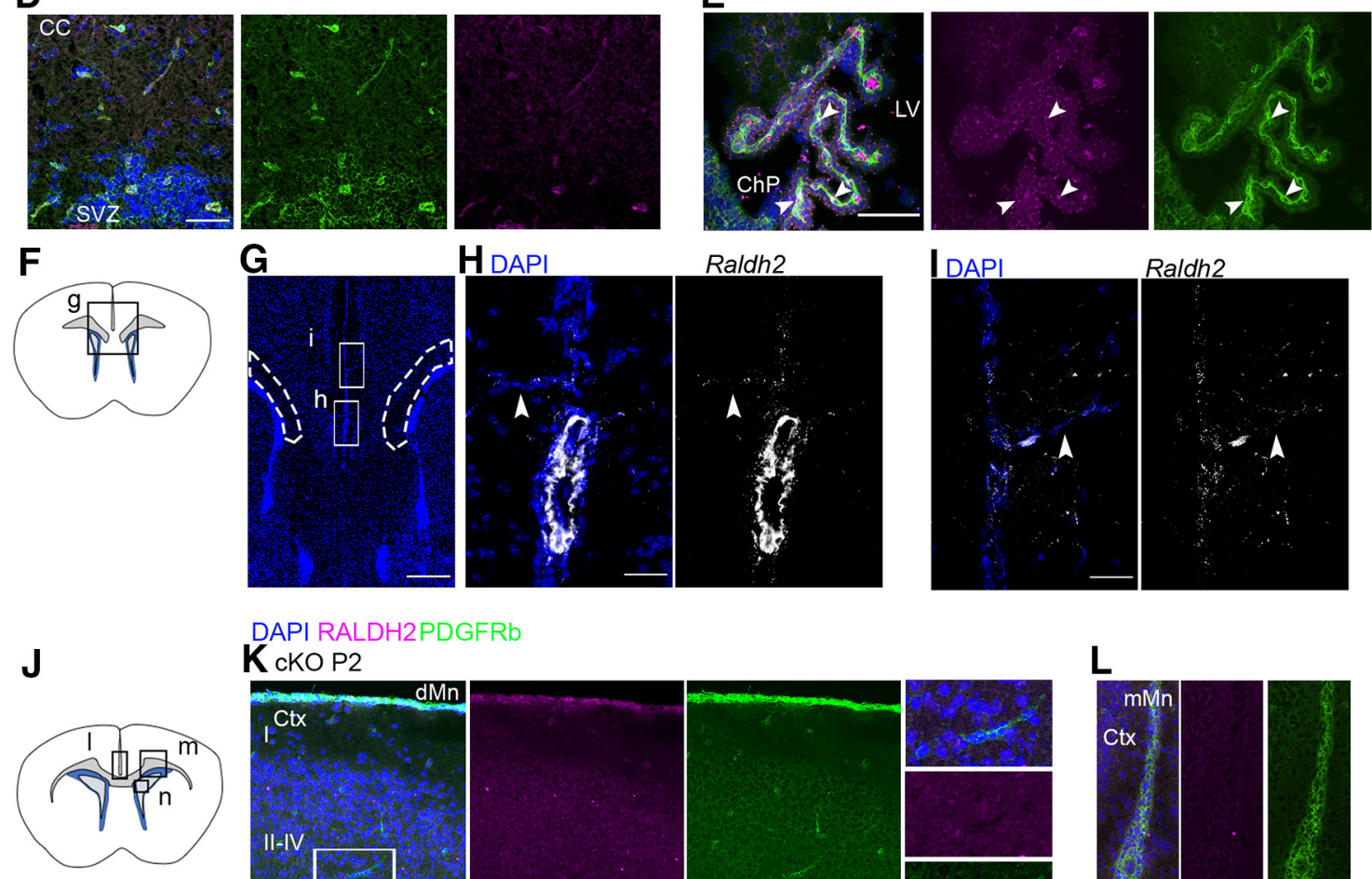

DAPI RALDH2PDGFRb

\section{K CKOP2}

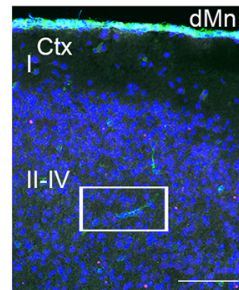

M

$\mathbf{N}$
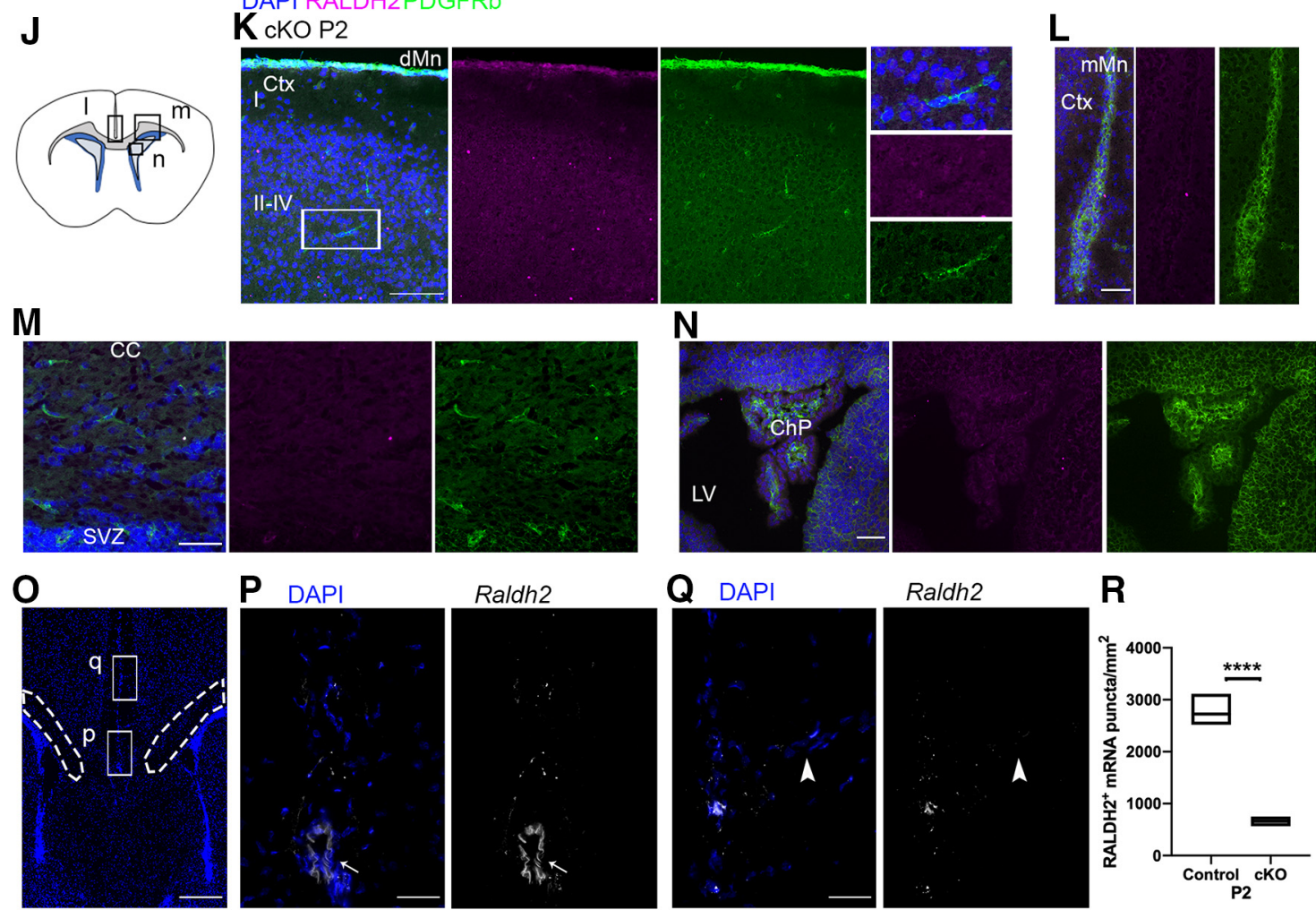

Figure 3. RALDH2 expression in the postnatal forebrain of control and cKO mice. $\boldsymbol{A}$, Coronal section illustrating regions imaged in panels $\boldsymbol{C}-\boldsymbol{E}$. B, RALDH2 (magenta) co-localizes with PDGFR $\beta$ (green) in the dorsal meninges and blood vessels, with a close up of RALDH2 staining in a PDGFR $\beta^{+}$cell (arrowhead) and a PDGFR $\beta^{+}$cell that does not express RALDH2 (chevron) in the cortex. $\boldsymbol{C}-\boldsymbol{E}$, RALDH2 co-localizes with PDGFR $\beta^{+}$cells (arrowheads) in the midline meninges $(\boldsymbol{C})$, CC $(\boldsymbol{D})$, choroid plexus stroma (E). $\boldsymbol{F}$, Coronal section illustrating the region imaged in G. G, Image indicating the midline meninges, CC (dotted line), SVZ (dense DAPI below dotted lines), and the regions seen in $\boldsymbol{H}, \boldsymbol{I} . \boldsymbol{H}, \boldsymbol{I}$, Raldh2 mRNA puncta are located in the midline meninges, blood vessels entering the brain 


\section{continued}

parenchyma (arrowheads), and a large blood vessel (bright white vertically oriented ellipse in the lower portion of $\boldsymbol{H}$ ). $\boldsymbol{J}$, Coronal section illustrating regions imaged in panels $\boldsymbol{L}-\boldsymbol{N}$. $\boldsymbol{K}, \mathrm{RALDH} 2$ (magenta) is undetectable in the dorsal meninges and parenchymal blood vessels of cKO mice, while PDGFR $\beta^{+}$cells (green) are still present; inset shows close up of a PDGFR $\beta^{+} \mathrm{RALDH}^{-}$cell in the cortex. $\boldsymbol{L}-\boldsymbol{N}$, RALDH2 staining is not present in the midline meninges $(\boldsymbol{L}), \mathrm{CC}(\boldsymbol{M})$, or choroid plexus $(\boldsymbol{N})$. $\boldsymbol{O}$, Image indicating the midline meninges, CC, SVZ, and the regions seen in $\boldsymbol{P}, \boldsymbol{Q} . \boldsymbol{P}, \boldsymbol{Q}$, Raldh2 mRNA puncta (white) in the meninges, penetrating blood vessels (arrowhead), and a large blood vessel (thin arrow) are reduced by $76 \%$ compared to controls. $\boldsymbol{R}$, Quantification of Raldh2 mRNA puncta per millimeter squared. Ctx, cortex; dMn, dorsal meninges; CC, corpus callosum; ChP, choroid plexus; SVZ, subventricular zone; LV, lateral ventricle; mMn, midline meninges; cKO, conditional knock-out. Scale bars: $200 \mu \mathrm{m}(\mathbf{G}, \mathbf{O}), 100 \mu \mathrm{m}(\boldsymbol{B}, \boldsymbol{C}, \boldsymbol{E}, \boldsymbol{K}, \boldsymbol{L}$, $\boldsymbol{N}), 25 \mu \mathrm{m}(\boldsymbol{D}, \boldsymbol{M})$, and $10 \mu \mathrm{m}(\boldsymbol{H}, \boldsymbol{I}, \boldsymbol{P}, \boldsymbol{Q})$. Floating bar plot, box: minimum to maximum value, line at median. $* * * * p<0.0001$

types at individual time points $\mathrm{P} 2-\mathrm{P} 21, F_{(7,35)}=7.933, p<$ $\left.0.0001^{\mathrm{e}}\right)$. In controls, total OLIG2 ${ }^{+}$cell numbers did not significantly change over the first three weeks of life (Fig. $5 D ; n$ is number of animals, $n=5 \mathrm{P} 2$ controls, $n=4 \mathrm{P} 21$ controls, unpaired $t$ test within genotype between individual time points $\mathrm{P} 2$ vs $\mathrm{P} 21$, one-tailed, $t_{(7)}=0.5192, p=$ $0.3098^{\dagger}$ ), while in $\mathrm{CKO}, \mathrm{OLIG}^{+}$cell numbers were reduced between P2 and P21 (Fig. $5 D ; n$ is number of animals, $n=6 \mathrm{P} 2 \mathrm{cKOs}, n=4 \mathrm{P} 21 \mathrm{cKOs}$, unpaired $t$ test within genotype between individual time points P2 vs P21, one-tailed, $\left.t_{(8)}=1.962, p=0.0427^{9}\right)$.

To determine whether the reduction of $\mathrm{OLIG}^{+}$cells in the cKO resulted from a decrease in OPCs or OLs, or both, the number of OPCs and OLs in cKO and control mice in the CC was quantified at P2, P7, P14, and P21 via immunofluorescence. Quantification of OPC numbers, based on co-expression of OLIG2 and PDGFR $\alpha$, a marker of OPCs (Fig. 5E,F), revealed that cKO and control mice had comparable PDGFR $\alpha^{+}$OPC numbers at all time points except P14, when cKO OPC numbers were de- creased by $>40 \%$ relative to controls (Fig. $5 G$; $n$ is number of animals, $n=6 /$ genotype, one-way ANOVA with Sidak's test for multiple comparisons between genotypes at individual time points $\mathrm{P} 2-\mathrm{P} 21, F_{(7,34)}=4.814$, $\left.p=0.0008^{\mathrm{h}}\right)$. Moreover, while controls displayed at least a two-fold increase in OPCs between P2 and P14 (Fig. 5G; $n$ is number of animals, $n=3-7$ controls/time point, one-way ANOVA with Sidak's test for multiple comparisons within genotype between individual time points P2-P21, $\left.F_{(3,7)}=6.728, p=0.0034^{i}\right)$, the pool of OPCs in cKO mice did not expand over the same time period. However, we found that PDGFR $\alpha^{+}$OPCs constituted a significantly larger percentage of the OLIG2 ${ }^{+}$ cell population in cKO mice than in controls at all time points (Fig. $5 H ; n$ is number of animals, $n=4-6 /$ genotype, one-way ANOVA with Sidak's test for multiple comparisons between genotypes at individual time points $\left.\mathrm{P} 2-\mathrm{P} 21, F_{(7,27)}=13.98, p<0.0001^{j}\right)$, suggesting that $\mathrm{OL}$ differentiation might be affected. To examine OLs, co-immunostaining analysis of OLIG2 and CC1,

\section{DAPI Laminin PDGFRb Co-labeled}

A Control P14
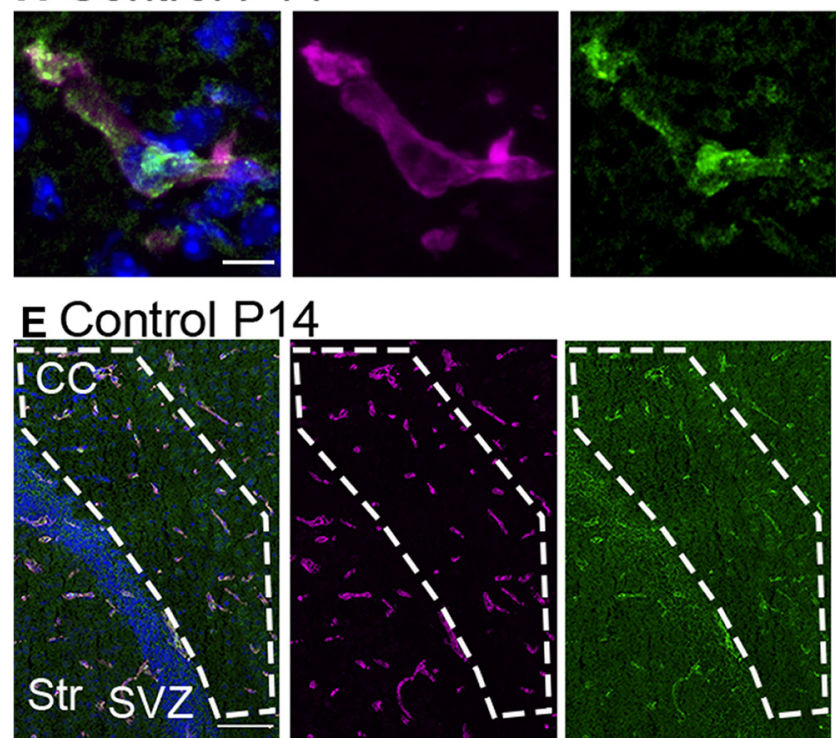
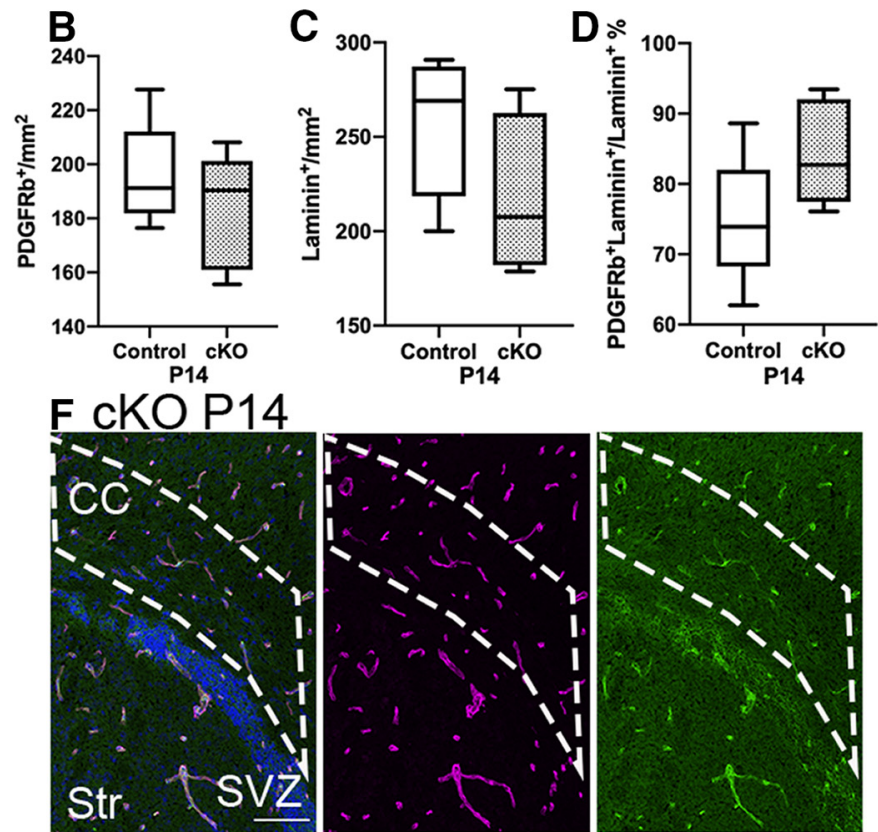

Figure 4. PDGFR $\beta^{+}$cells and vasculature are normal in the Raldh2 cKO. A, PDGFR $\beta^{+}$cells (green) co-localize with Laminin on blood vessels. B, Quantification of PDGFR $\beta^{+}$structures. C, Quantification of Laminin ${ }^{+}$structures. $\boldsymbol{D}$, Percentage of Laminin ${ }^{+}$structures co-localizing with PDGFR $\beta$. $\boldsymbol{E}, \boldsymbol{F}$, Immunofluorescence for Laminin (magenta) and PDGFR $\beta$ (green), in the CC (area within the white dashed line) of control and cKO mice; co-localization shown in white. Mn, meninges; Ctx, cortex; CC, corpus callosum; SVZ, subventricular zone; LV, lateral ventricle; ChP, choroid plexus; Str, striatum; cKO, conditional knock-out. Scale bars: $50 \mu \mathrm{m}(\boldsymbol{E}, \boldsymbol{F})$ and $5 \mu \mathrm{m}(\boldsymbol{A})$. Box and whiskers plot, box: 25th and 75th percentile, whiskers: minimum to maximum value, line at median. 


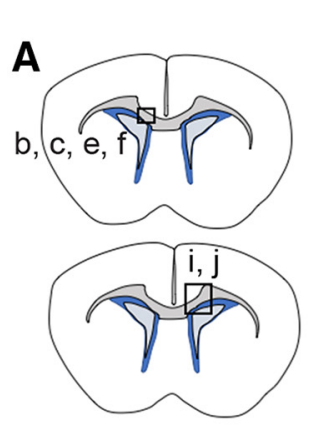

DAPI OLIG2

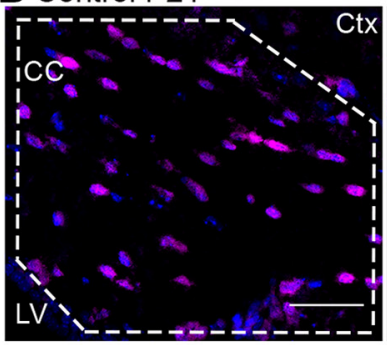

$\mathbf{C}_{\text {cKO P21 }}$
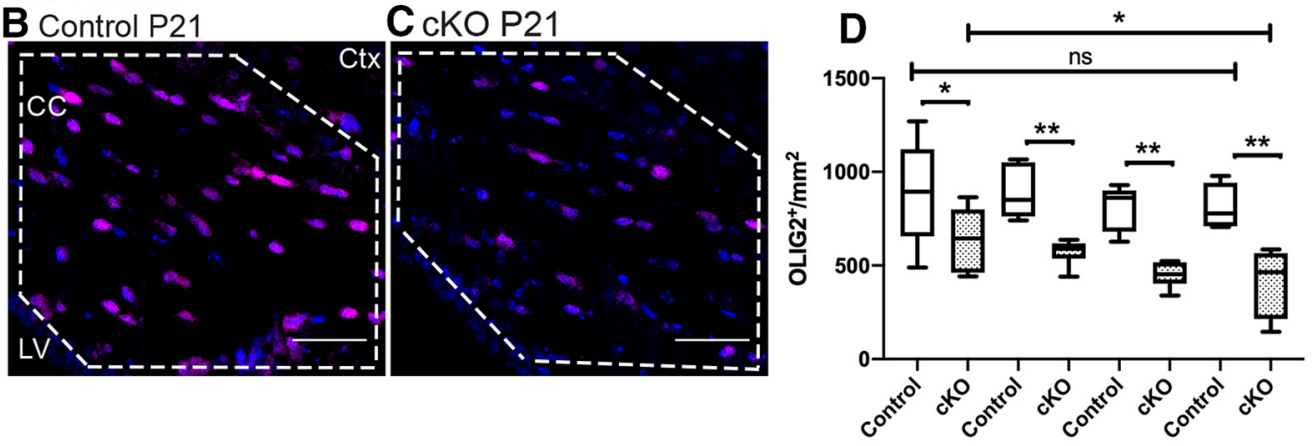

OLIG2 PDGFRa

E Control P14

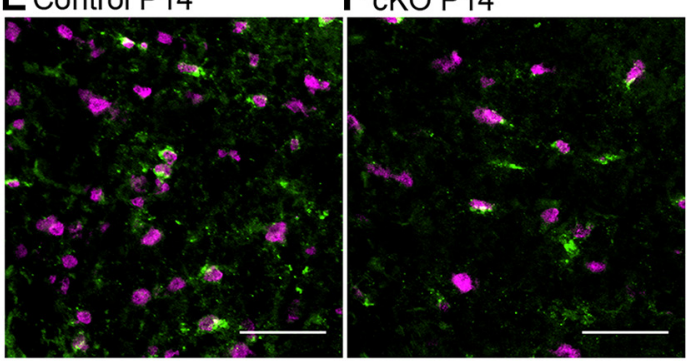

F cKO P14

G

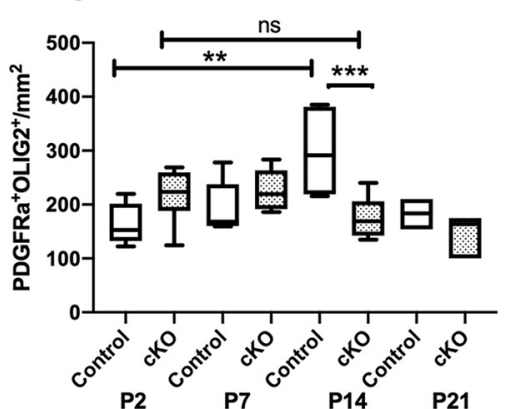

H

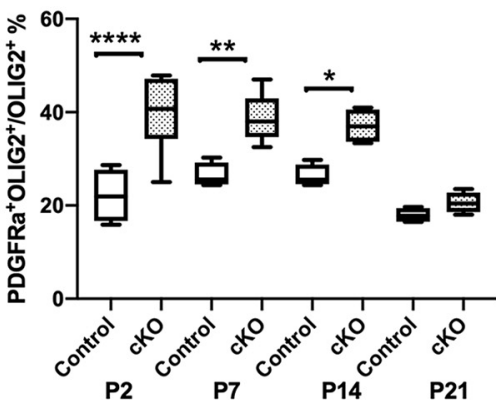

OLIG2 CC1 Co-labeled
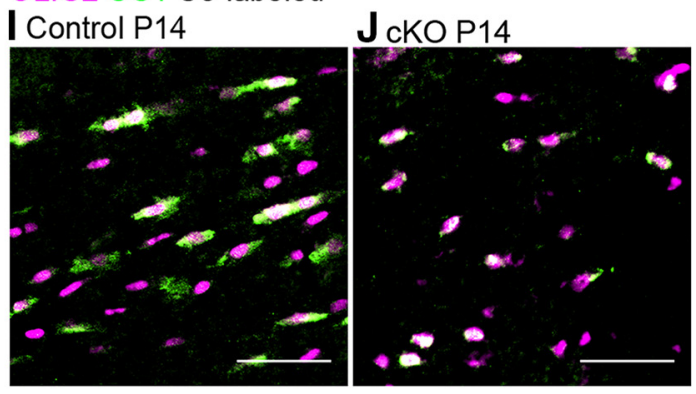

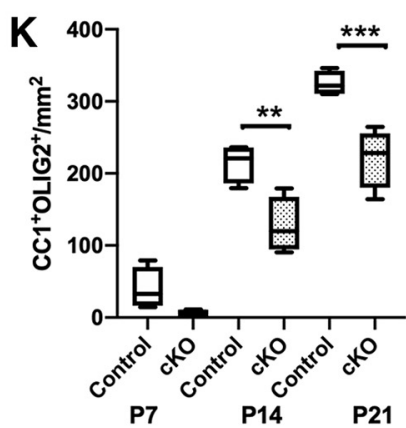

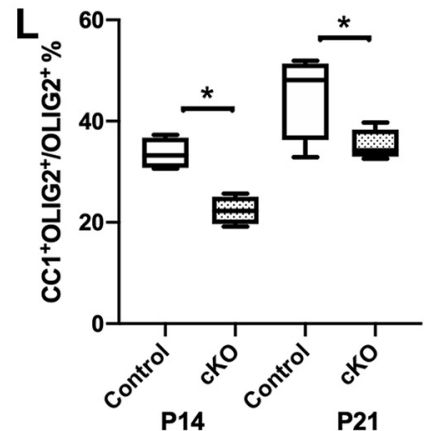

DAPI NF200 PLP

\section{MControl P21}

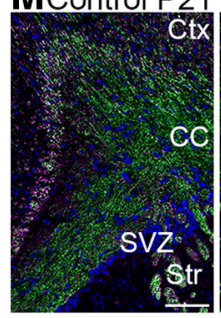

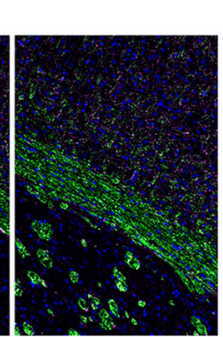

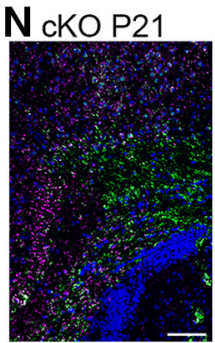

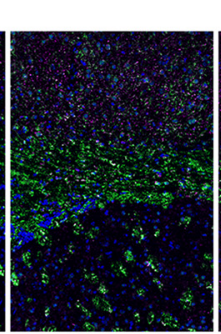

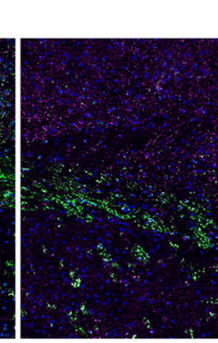

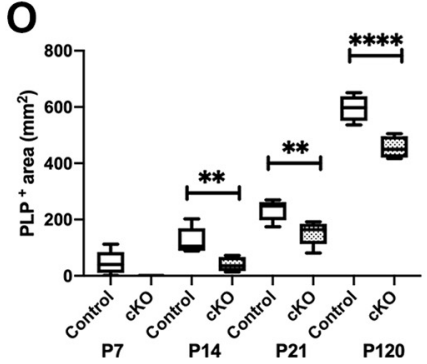

Figure 5. Raldh2 cKO results in reduced numbers of OPCs and OLs. $\boldsymbol{A}$, Coronal section illustrating the regions imaged in $\boldsymbol{B}, \boldsymbol{C}, \boldsymbol{E}, \boldsymbol{F}$, and $\boldsymbol{M}, \boldsymbol{N}$ (top) and $\boldsymbol{I}, \boldsymbol{J}$ (bottom). $\boldsymbol{B}$, Control mice have abundant OL lineage cells (OLIG2, magenta; CC, dotted line) and OLIG2 ${ }^{+}$cell numbers remain stable throughout the first three weeks of postnatal life. $\boldsymbol{C}, \mathrm{cKO}$ mice have significantly fewer OLIG2 ${ }^{+}$cells at all time points examined. $\boldsymbol{D}$, Quantification of OLIG2 ${ }^{+}$cell number in control versus cKO mice at each time point. $\boldsymbol{E}, \boldsymbol{F}$, Control and cKO mice both have OPCs [co-labeled by PDGFR $\alpha$ (green) and OLIG2 (magenta)]. G, control and cKO mice have comparable total PDGFR $\alpha^{+}$OLIG2 ${ }^{+}$cell numbers at all time points except P14, when cKO mice have fewer, and while controls displayed at least a two-fold increase in OPCs between P2 and P14, the pool of OPCs in cKO mice did not expand over the same time period. $\boldsymbol{H}$, More OLIG2 ${ }^{+}$cells are co-labeled with PDGFR $\alpha$ in cKO mice than controls. $\boldsymbol{I}, \boldsymbol{J}$, Control and cKO mice both have mature OLs [co-labeled by CC1 (green) and OLIG2 (magenta)]. $\boldsymbol{K}$, cKO mice have reduced $\mathrm{CC} 1^{+} \mathrm{OLIG} 2^{+}$cell numbers at P14 and P21. $\boldsymbol{L}$, In cKO mice, fewer OLIG2 ${ }^{+}$cells are co-labeled with CC1 than in controls. $\boldsymbol{M}, \boldsymbol{N}$, Control mice have more $\mathrm{PLP}^{+}$labeled area (green) than cKO mice at P14, P21, and P120; NF200 (magenta) labels axons. O, Quantification of reduced PLP labeling. CC, corpus callosum; Ctx, cortex; LV, lateral ventricle; SVZ, subventricular zone; Str, striatum; cKO, conditional knock-out. Scale bars: $100 \mu \mathrm{m}(\boldsymbol{M}, \boldsymbol{N})$ and $50 \mu \mathrm{m}(\boldsymbol{B}, \boldsymbol{C}, \boldsymbol{E}, \boldsymbol{F}, \boldsymbol{I}, \boldsymbol{J})$. Box and whisker plot, box: 25th and 75th percentile, whiskers: minimum to maximum value, line at median. Floating bar plot, box: minimum to maximum value, line at median. $* p<0.05, * * p$ $<0.01, * * * p<0.001, * * * * p<0.0001$. ns $=$ not significant. 
which is involved in mature OL production (Lang et al., 2013), was performed at P7, P14, and P21 (Fig. 5/,J). We found that the number of $\mathrm{CC} 1^{+} \mathrm{OLs}$ in the CC progressively increased from P7 to P21 in both the cKO and control. However, the cKO displayed fewer $\mathrm{CC}_{1}{ }^{+}$ OLs compared to controls at P14 and P21 (Fig. $5 K ; n$ is number of animals, $n=4 /$ genotype, one-way ANOVA with Sidak's test for multiple comparisons between genotypes at individual time points P7-P21, $F_{(5,18)}=$ 68.26, $\left.p<0.0001^{\mathrm{k}}\right)$. Correspondingly, the percentage of $\mathrm{CC}_{1}{ }^{+} \mathrm{OLs}$ was significantly reduced among the total $\mathrm{OLIG}^{+}$pool in cKO mice compared to control littermates (Fig. $5 L ; n$ is number of animals, $n=4 /$ genotype, one-way ANOVA with Sidak's test for multiple comparisons between genotypes at individual time points P14$\left.\mathrm{P} 21, F_{(3,12)}=13.96, p=0.0003^{\prime}\right)$. To confirm the OL deficit, we quantified the expression of proteolipid protein (PLP), an integral myelin protein, in the CC of cKO and control mice. We found that $\mathrm{PLP}^{+}$labeling in the cKO was reduced at P14 and P21, contrasting sharply with its high expression in control brains at the same time points (Fig. $5 M-O$; $n$ is number of animals, $n=$ 5-6/genotype, one-way ANOVA with Sidak's test for multiple comparisons between genotypes at individual time points P7-P120, $\left.F_{(7,32)}=134.2, p<0.0001^{\mathrm{m}}\right)$. We also found that this reduction in PLP persisted at four months (P120), suggesting this phenotype is a deficit in OL development rather than a delay. Together, our results suggest that endogenous RALDH2 supports the differentiation of OPCs into OLs.

\section{Loss of RALDH2 reduces NSC survival and Gli1 expression in the SVZ but does not affect proliferation or survival of OL lineage cells}

Reduced OPC numbers in the CC of two-week-old cKO mice could be due to decreased OPC proliferation or increased OPC death. To determine whether RALDH2 affects OPC proliferation, immunofluorescence analysis of PDGFR $\alpha$ and KI67 co-labeling in the CC was performed at P2, P7, P14, and P21 (Fig. 6B,C). We found the total numbers of $\mathrm{KI}_{6} 7^{+}$cells were not significantly different between cKO and controls at any time point examined (Fig. 6D). Moreover, the number of proliferating OPCs between CKO and controls were similar to each other across all time points (Fig. 6E). To determine whether increased cell death played a role in the overall OLIG2 ${ }^{+}$ cell deficit in the cKO mice, the TUNEL assay was performed to detect cleaved DNA in dying cells at P2, P7, and P14. There was a significant reduction of TUNEL ${ }^{+}$ cells between P2 and P7 in the CC and SVZ of control mice (Fig. $6 F ; n$ is number of animals, $n=8 \mathrm{P} 2$ controls, $n=10$ P7 controls, unpaired $t$ test within genotype between individual time points P2 vs P7, one-tailed, $t_{(16)}=$ 4.727, $\left.p<0.0001^{\mathrm{n}}\right)$. This reduction was not present in cKO mice between P2 and P7 (Fig. 6F; $n$ is number of animals, $n=8 \mathrm{P} 2 \mathrm{cKOs}, n=10 \mathrm{P} 7 \mathrm{cKOs}$, unpaired $t$ test within genotype between individual time points P2 vs P7, one-tailed, $t_{(16)}=1.222, p=0.1197^{\circ}$ ). At P2, control and cKO mice had similar levels of TUNEL ${ }^{+}$cells, however, the number of TUNEL ${ }^{+}$cells in the cKO was significantly increased at P7 and P14 compared to control littermates (Fig. $6 F ; n$ is number of animals, $n=10$ /genotype, oneway ANOVA with Sidak's test for multiple comparisons between genotypes at individual time points P2-P14, $\left.F_{(5,50)}=16.24, p<0.0001^{\mathrm{p}}\right)$. Interestingly, we did not find TUNEL co-labeling with OLIG2 in either control or cKO mice (Fig. 6G,H). Instead, we found that the majority of $\mathrm{TUNEL}^{+}$cells in the cKO mice was detected at the SVZ and co-labeled with the NSC marker, Nestin (Fig. 6/). These results suggested that Raldh2 cKO did not affect OPC proliferation or survival, but impaired NSC survival in the SVZ.

We also examined whether loss of RALDH2 expression affected microglial development. Microglial activation, including increased proliferation, can be mitigated by RA signaling (Dheen et al., 2005; Takamura et al., 2017), and changes in microglial function could impact OL development. By performing immunofluorescence staining for ionized calcium-binding adaptor molecule 1 (IBA1) at P7, 14 , and P21, we found no significant differences between genotypes in terms of IBA $1^{+}$cell number (Fig. $6 J-L ; n$ is number of animals, $n=3-4 /$ genotype, one-way ANOVA with Sidak's test for multiple comparisons between genotypes at individual time points P7-P21, $F_{(5,17)}=1.028, p=$ $\left.0.4326^{9}\right)$, suggesting that loss of RALDH2 does not impact OL lineage cell development through changes in microglial cell number.

The persistent cell death among NSCs in Raldh2 cKO mice between P2 and P14 led us to ask whether OPC production from NSCs in the SVZ was affected in the absence of RALDH2. It has previously been demonstrated that transient SHH signaling in NSCs in the SVZ contributes to the generation of the majority of OPCs in the postnatal CC (Tong et al., 2015; Traiffort et al., 2016; Sanchez and Armstrong, 2018; Winkler et al., 2018). To determine whether decreased $\mathrm{SHH}$ signaling contributed to OL lineage cell deficits in Raldh2 cKO mice, we performed RNAscope in situ hybridization analysis for the expression of Gli1, an indicator of active SHH signaling, and Olig2 (Fig. 7B,C,F,G). We found that cKO mice displayed an almost $50 \%$ reduction of Gli1 transcripts in the SVZ compared to controls at P2 (Fig. 7D; $n$ is number of animals, $n=5$ controls, $n=7$ cKOs, unpaired $t$ test between genotypes at P2, one-tailed, $t_{(10)}=3.251, p=$ 0.00447 , and the number of Gli1 ${ }^{+}$puncta per cell was also reduced (Fig. 7E; $n$ is number of cells included in the analysis of three mice per genotype, $n=66$ in controls, $n$ $=80$ in cKOs, unpaired $t$ test between genotypes at $\mathrm{P} 2$, one-tailed, $\left.t_{(144)}=5.363, p<0.0001^{\mathrm{s}}\right)$. At the transition between the CC and subcallosal SVZ, we detected significantly fewer Gli1 ${ }^{+}$Olig2 ${ }^{+}$cells in cKO mice than controls (Fig. $7 F-H ; n$ is number of animals, $n=3$ /genotypes, unpaired $t$ test between genotypes at $\mathrm{P} 2$, one-tailed, $t_{(4)}=$ 12.36, $\left.p=0.0001^{\dagger}\right)$. These results suggest that loss of RALDH2 expression could have affected $\mathrm{SHH}$-mediated production of subcortical white matter OPCs from the subcallosal SVZ. 
A
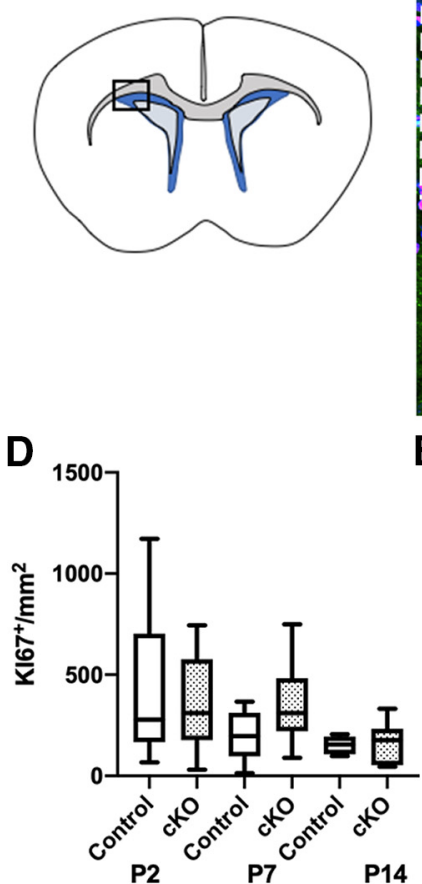

\section{DAPI KI67 PDGFRa Co-labeled}

B Control P14

C cKO P14

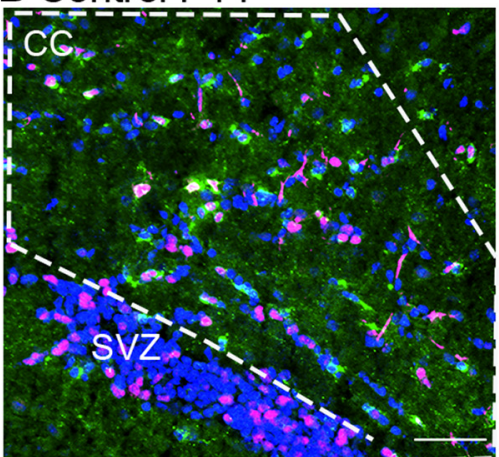

E

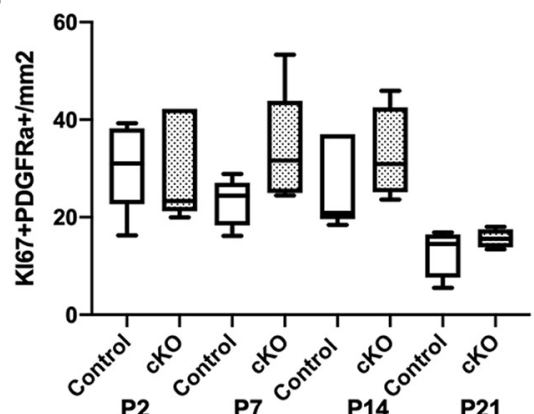

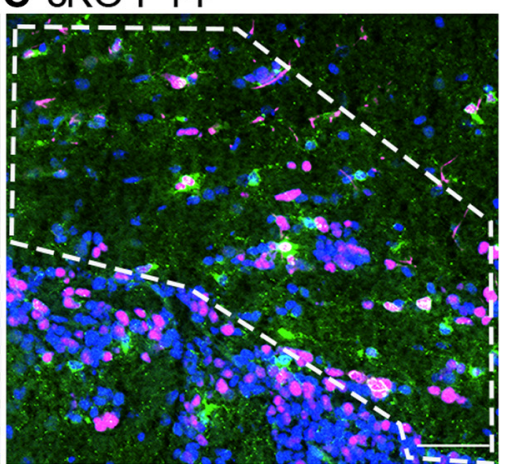

$\mathbf{F}$

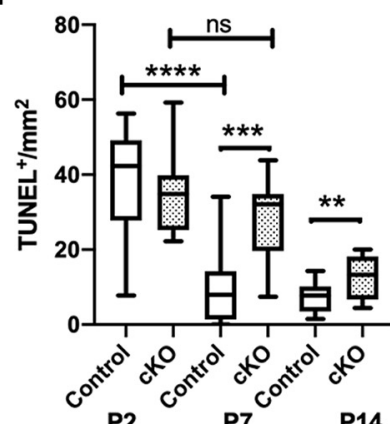

DAPI OLIG2 TUNEL

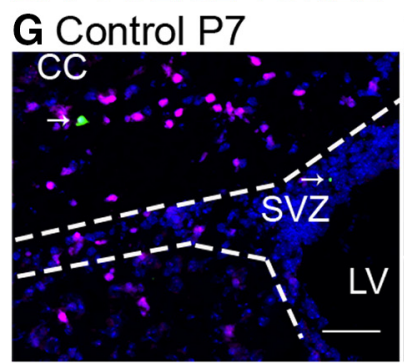

\section{H cKO P7}
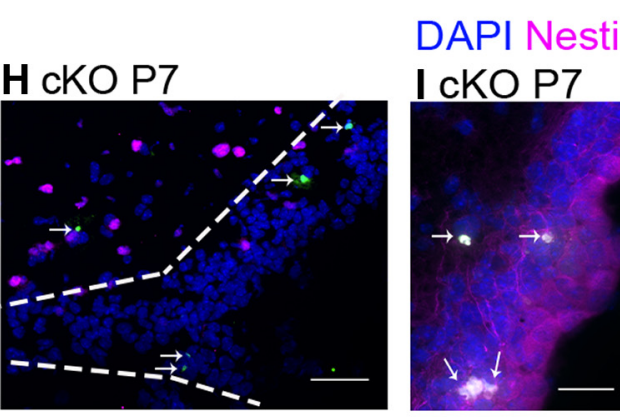

DAPI IBA1

J Control P14

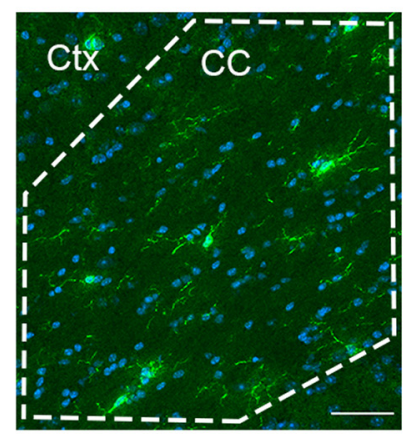

K cKO P14

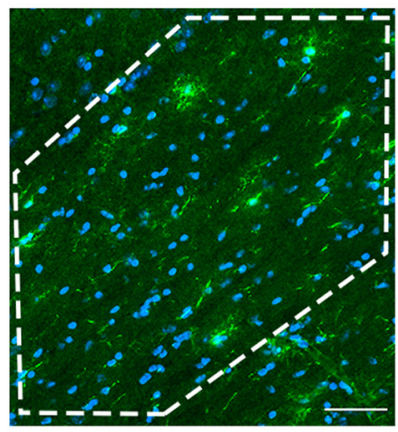

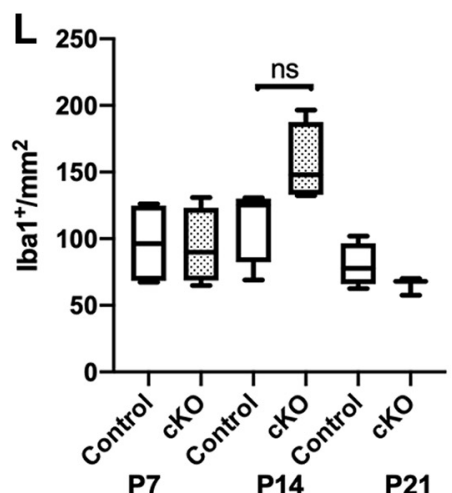

Figure 6. NSC survival is reduced in the Raldh2 cKO. $\boldsymbol{A}$, Coronal section illustrating the regions imaged in the other panels. $\boldsymbol{B}$, $\boldsymbol{C}$ Control and cKO mice both have proliferating PDGFR $\alpha^{+}$cells (green) identified by co-labeling (white) with KI67 (magenta), and

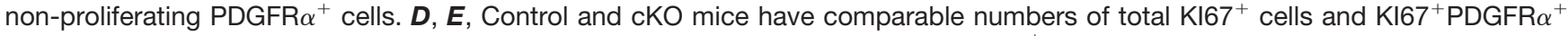
cells at all time points. $\boldsymbol{F}$, Between P2 and P7 in control animals, the number of TUNEL ${ }^{+}$cells dropped significantly. Between P2 and $\mathrm{P} 7$ in cKO mice, TUNEL ${ }^{+}$cell numbers were unchanged. At P7 and P14, cKO mice had significantly more $\mathrm{TUNEL}^{+}$cells than controls. $\boldsymbol{G}, \boldsymbol{H}$, Dying cells identified by labeling with TUNEL (green, thin arrow) were present in the CC and SVZ (delineated by dotted lines) of both controls and cKO, though no OLIG2 ${ }^{+}$cells were co-labeled with TUNEL. I, In the cKO SVZ, $76 \%$ of all TUNEL ${ }^{+}$cells were co-labeled by Nestin [magenta, co-labeled cells are white (thin arrow)]. $\boldsymbol{J}, \boldsymbol{K}$, Immunofluorescence for IBA $1^{+}$in the CC of control and 
continued

cKO mice. $\boldsymbol{L}$, Quantification of the number of IBA1 ${ }^{+}$cells shows no significant difference between groups; a transient increase in IBA1 ${ }^{+}$cells appears at P7 in cKO mice but does not reach significance. CC, corpus callosum; SVZ, subventricular zone; LV, lateral ventricle; cKO, conditional knock-out. Scale bars: $50 \mu \mathrm{m}(\boldsymbol{B}, \boldsymbol{C}, \boldsymbol{G}, \boldsymbol{H}, \boldsymbol{J}, \boldsymbol{K})$ and $25 \mu \mathrm{m}(\boldsymbol{I})$. Box and whisker plot, box: 25th and 75th percentile, whiskers: minimum to maximum value, line at median. $* * p<0.01, * * * p<0.001, * * * * p<0.0001$. ns $=$ not significant.

\section{Loss of RALDH2 reduces GFAP labeling in the CC and alters cortical neuron numbers}

The possibility that loss of Raldh2 affects OL lineage cell numbers via altered NSC function led us to ask whether other NSC-derived cell populations, specifically cortical neurons and astrocytes, were also impacted. First, we asked if astrocytes in the $\mathrm{CC}$ were affected in the Raldh2 cKO mice by performing glial fibrillary acidic protein (GFAP) immunostaining. We found that cKO mice exhibited a two-fold decrease in $\mathrm{GFAP}^{+}$area at all time points examined (Fig. 8A-C; $n$ is number of animals, $n=$ 4-6/genotype, one-way ANOVA with Sidak's test for multiple comparisons between genotypes at individual time points P2-P21, $\left.F_{(7,25)}=52.95, p<0.0001^{4}\right)$. These findings suggest that astrocyte development is altered in the absence of RALDH2.

Next, to examine cortical neurons, we counted the number of late-born, upper layer neurons based on SATB2 staining. We found a significant increase in SATB2 $^{+}$neuron numbers in $\mathrm{CKO}$ mice at $\mathrm{P} 2$ relative to controls (Fig. $8 E-G$; $n$ is number of animals, $n=3-5$ / genotype, unpaired $t$ test between genotypes at $\mathrm{P} 2$, onetailed, $\left.t_{(6)}=2.874, p=0.0141^{\mathrm{V}}\right)$. Moreover, SATB2 ${ }^{+}$ nuclei in cKO mice seemed smaller than those in controls. Next, we counted the number of early-born, deep layer neurons based on CTIP2 ${ }^{+}$staining of layer 5 neurons and $\mathrm{TBR}^{+}{ }^{+}$staining of layer 6 neurons in control and cKO mice at P2. We found that TBR $1^{+}$and $\mathrm{CTIP} 2^{+}$deep layer neurons were significantly reduced in $\mathrm{CKO}$ mice relative to control littermates (Fig. 8H-K; quantification of CTIP2 ${ }^{+}$ cells: $n$ is number of animals, $n=4 /$ genotype, unpaired $t$ test between genotypes at P2, two-tailed, $t_{(6)}=5.631, p$ $=0.0013^{\mathrm{w}}$; quantification of TBR $1^{+}$cells: $n$ is number of animals, $n=3 /$ genotype, unpaired $t$ test between genotypes at P2, two-tailed, $t_{(4)}=5.298, p=0.0061^{\times}$). Gross forebrain morphology was unaffected and cortical layers were clearly discernable by DAPI staining, but cortical thickness in Raldh2 cKO mice was reduced relative to controls at P2 (Fig. $8 L-N ; n$ is the number of animals, $n=$ 3/genotype, unpaired $t$ test between genotypes at $\mathrm{P} 2$,
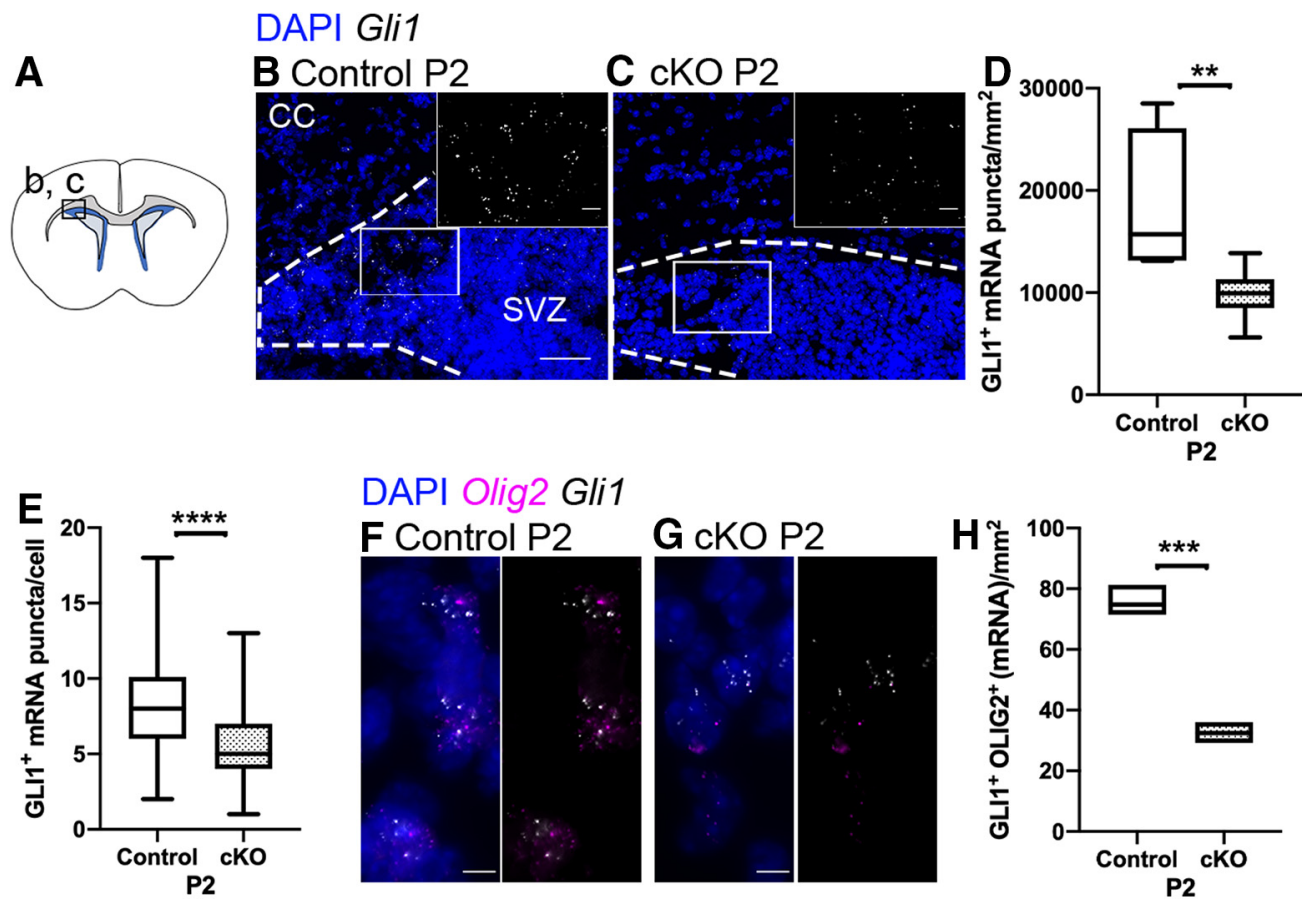

Figure 7. Gli1 expression is reduced in the SVZ in Raldh2 cKO mice. $\boldsymbol{A}$, Coronal section illustrating the region imaged in $\boldsymbol{B}, \boldsymbol{C}$. $\boldsymbol{B}, \boldsymbol{C}$, In controls and CKO mice, Gli1 mRNA puncta (white) are found in the SVZ (delineated by dotted lines) and the transition from the SVZ into the CC (area flanking the top dotted line in $\boldsymbol{B}, \boldsymbol{C}$ ). $\boldsymbol{D}$, The total number of Gli1 puncta in the SVZ and its border with the CC is reduced in cKO at P2 relative to controls. $\boldsymbol{E}$, The number of Gli1 mRNA puncta per cell is reduced in cKO mice. $\boldsymbol{F}$, $\boldsymbol{G}$, Gli1 $^{+}$Olig2 ${ }^{+}$-co-labeled cells (white and magenta) cells are found at the border between the SVZ and CC in controls and cKO. $\boldsymbol{H}$, The number of $\mathrm{Gli1}^{+}$Olig2 ${ }^{+}$cells is reduced in CKO mice. CC, corpus callosum; SVZ, subventricular zone; LV, lateral ventricle; cKO, conditional knock-out. Scale bars: $50 \mu \mathrm{m}(\boldsymbol{B}, \boldsymbol{C})$ and $5 \mu \mathrm{m}(\boldsymbol{F}, \boldsymbol{G})$. Box and whisker plot, box: 25th and 75th percentile, whiskers: minimum to maximum value, line at median. Floating bar plot, box: minimum to maximum value, line at median. $* * p<0.01, * * * p<$ $0.001, * * * * p<0.0001$ 
DAPI OLIG2 GFAP
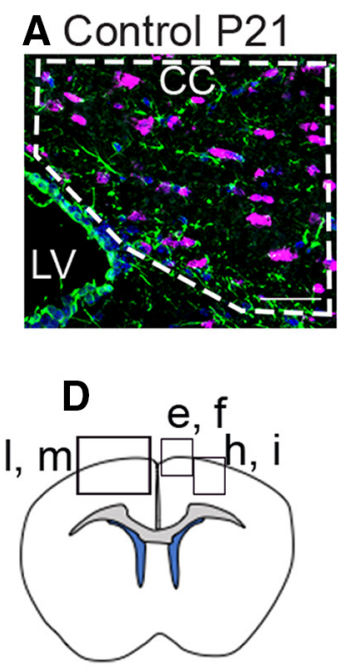
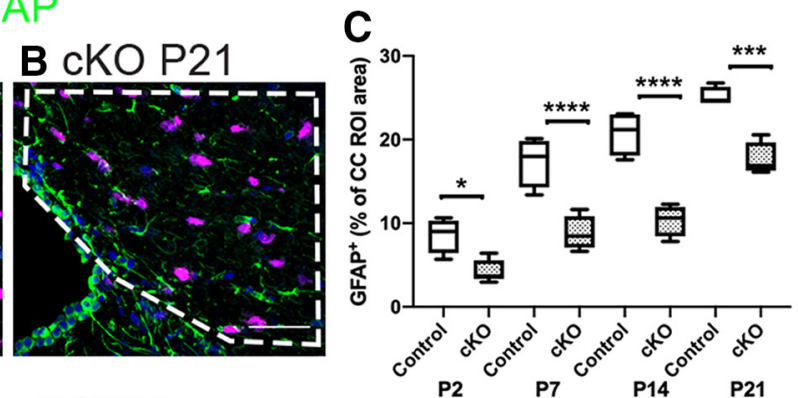

TBR1 CTIP2
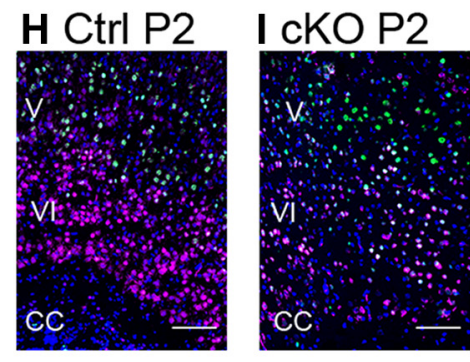

DAPI

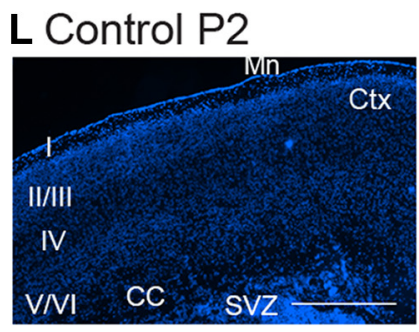

SATB2
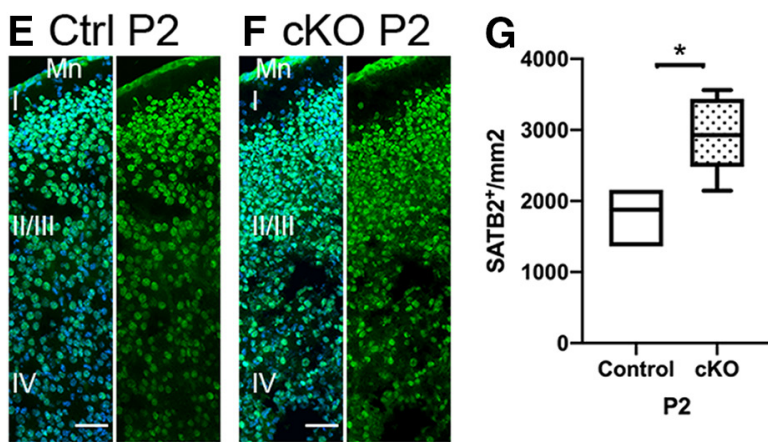

P2

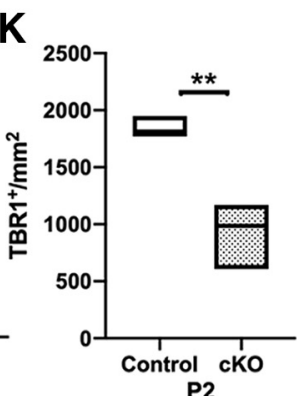

$\mathbf{N}$ M cKO P2

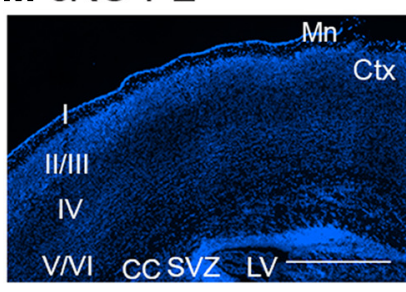

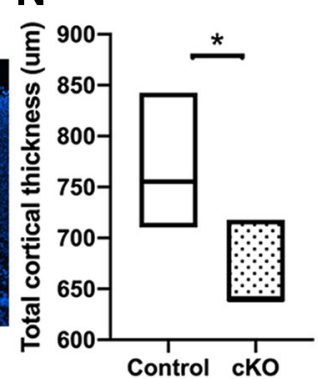

P2

Figure 8. Other NSC-derived cell types are reduced by loss of RALDH2. $\boldsymbol{A}, \boldsymbol{B}$, Control and cKO mice both have GFAP ${ }^{+}$expression in the CC (dotted lines). OLIG2 marks OL lineage cells and is included to provide contrast. $\boldsymbol{C}$, The area of CC that is labeled by GFAP is significantly reduced in cKO mice relative to controls at all time points examined. $\boldsymbol{D}$, Coronal section illustrating the regions imaged in $\boldsymbol{E}, \boldsymbol{F}, \boldsymbol{H}, \boldsymbol{I}, \boldsymbol{L}, \boldsymbol{M}$. $\boldsymbol{E}-\boldsymbol{G}$, cKO mice have significantly more SATB2 ${ }^{+}$neurons (green) than controls. $\boldsymbol{H}$, $\boldsymbol{I}$, cKO mice have significantly fewer layer 6 (TBR1, magenta) and layer 5 (CTIP2, green) neurons than control mice at P2. J, Quantification of CTIP2 ${ }^{+}$cell reduction in cKO mice. $\boldsymbol{K}$, Quantification of TBR $1^{+}$cell reduction in cKO mice. $\boldsymbol{L}, \boldsymbol{M}$, Cortical thickness is reduced in cKO mice. $\boldsymbol{N}$, Quantification of cortical thickness. CC, corpus callosum; LV, lateral ventricle; Ctx, cortex (with layers 1-6 in roman numerals); SVZ, subventricular zone; Mn, meninges; cKO, conditional knock-out. Scale bars: $200 \mu \mathrm{m}(\boldsymbol{L}, \boldsymbol{M}), 100 \mu \mathrm{m}(\boldsymbol{A}, \boldsymbol{B}), 50 \mu \mathrm{m}(\boldsymbol{H}, \boldsymbol{I})$, and $25 \mu \mathrm{m}(\boldsymbol{E}, \boldsymbol{F})$. Box and whisker plot, box: 25 th and 75 th percentile, whiskers: minimum to maximum value, line at median. Floating bar plot, box: minimum to maximum value, line at median. $* p<0.05$, $* * p<0.01, * * * p<0.001, * * * * p<0.0001$. 
one-tailed, $t_{(4)}=2.20, p=0.0453^{y}$ ). As was observed for $\mathrm{SATB2}^{+}$upper layer neurons, we found that nuclei of deep layer neurons appeared smaller compared to control mice. The apparent reduction in nucleus size (and presumably cell soma size) among cortical neurons, as well as the visible decrease in space between the neurons may explain the reduced cortical thickness in cKO mice. This is reminiscent of cell size scaling, which has been observed as a method to avoid increasing brain size in the case of increased neuron number (Herculano-Houzel et al., 2006).

Overall, our results suggest that endogenous RALDH2 influences not only the production and maturation of OPCs in the CC, but also the development cortical neurons and callosal astrocytes.

\section{Discussion}

\section{RALDH2 expression in the postnatal mouse forebrain}

Our goal was to determine whether OL development requires RALDH2. First, we confirmed that postnatal RALDH2 expression overlaps with that of PDGFR $\beta$ in the meninges, along gray and white matter blood vessels, and in the choroid plexus, all of which is consistent with previous literature (Yamamoto et al., 1996; Niederreither et al., 1997; Smith et al., 2001; Wagner et al., 2002; Kelly et al., 2016; Vanlandewijck et al., 2018). Additionally, several papers have shown that RALDH2 is found in isolated hippocampal and hindbrain neurons, but we did not observe RALDH2 expression in forebrain neurons (Smith et al., 2001; Wagner et al., 2002). Not all of these studies, however, found the same spatiotemporal expression profiles of RALDH2.

These incongruities may result from differences in methodologies, but some may be physiologically relevant and inherent to RALDH2. For example, RALDH2 protein expression patterns are variable within samples and within time points in the olfactory neuroepithelium where retinoids influence proliferation, differentiation, and survival of olfactory sensory neurons (Asson-Batres et al., 2003; Asson-Batres and Smith, 2006; Hägglund et al., 2006). In fact, several studies propose that there is discontinuity between Raldh2 mRNA and protein expression in vivo (Niederreither et al., 1997; Norlin et al., 2001; Asson-Batres and Smith, 2006).These previous findings may explain why, in control animals, we found abundant Raldh2 transcripts in the meninges but none in the brain parenchyma, despite RALDH2 protein being visible in perivascular cells.

\section{RALDH2 ${ }^{+}$cell identity and knock-out of RALDH2 in $\mathrm{Ng} 2-\mathrm{Cre}$ lineage cells}

This inherent difficulty of RALDH2 detection complicates the task of characterizing RALDH2 ${ }^{+}$cells in the postnatal forebrain. Several studies describe RALDH2 expression in $\mathrm{NG}^{+}$cells in adult spinal cord parenchyma, ostensibly pericytes (Mey et al., 2005; Kern et al., 2007), but others show that RALDH2 protein and mRNA are found primarily in Col1a $1^{+}$PDGFR $\beta^{+}$cells in a "fibroblastlike" population of perivascular cells (FB cells) and not $\mathrm{Ng}^{+}$pericytes (Kelly et al., 2016; Vanlandewijck et al.,
2018). There are two FB subpopulations (FB1 and FB2) that differ largely in terms of their collagen expression patterns, and Raldh2 and $\mathrm{Ng} 2$ are found in varying amounts in both subgroups. Here, through NG2 and PDGFR $\beta$ staining, we identified $\mathrm{NG} 2^{+} \mathrm{PDGFR} \beta^{-}$cells (OPCs), NG2 ${ }^{+}$PDGFR $\beta^{+}$cells (mural cells, consisting of pericytes and SMCs, and likely some FB2 cells), and NG2-PDGFR $\beta^{+}$cells (likely FB1 and 2 cells). We found that RALDH2 ${ }^{+}$cells were always PDGFR $\beta^{+}$while not all PDGFR $\beta^{+}$cells were RALDH2 ${ }^{+}$. This is consistent with our interrogation of the data in the online gene expression database generated by Vanlandewijck et al. (2018), leading to the conclusion that only a subset of Pdgfr $\beta^{+}$ perivascular cells (i.e., FB cells) express Raldh2.

Raldh2 excision in FB cells of the Ng2-Cre:Raldh2 $2^{\text {flox/flox }}$ mouse is likely dependent on their expression of NG2 early in development. Several single cell RNA sequencing studies discovered an $\mathrm{Ng}^{+} \mathrm{Co} / 1 \mathrm{a} 1^{+}$population present in the embryonic mouse brain (Marques et al., 2016, 2018), likely the embryonic precursors of postnatal Col1a $1^{+} \mathrm{RALDH}_{2}{ }^{+} \mathrm{FB}$ cells. While $\mathrm{Ng} 2$ expression is low in postnatal FBs, even transient expression and Cre activation during embryonic development could be enough to affect their expression of Raldh2 later on. For example, transient $\mathrm{Ng} 2$ expression in NSCs is sufficient to activate the reporter in the astrocytic progeny of the Ng2-CreBAC: Z/EG line (Zhu et al., 2008). The Col1a1 ${ }^{+} \mathrm{RALDH}^{+}{ }^{+}$population in the forebrain expands in the first three postnatal weeks (Kelly et al., 2016). This is also at peak OPC production from the SVZ (P0-P14) and a time when the first mature OLs appear in the CC (P8; Foran and Peterson, 1992; Dai et al., 2015). This may constitute an important time and place for interactions between RALDH2 ${ }^{+}$ perivascular cells, NSCs, and OPCs that could influence OLC development.

\section{RALDH2 amid a multiplicity of RALDHs}

RALDH1-RALDH3 are all expressed in forebrain structures, and while each enzyme possesses its own unique spatiotemporal expression profile, a given enzyme's timing or region of expression may be very close to that of another RALDH isozyme. Importantly, RALDH3 expression in the superior layers of the cortex at P1.5 is found in bipolar, early postmigratory neurons, and a few days later at P5, it is present during arborization of these neurons, suggesting a role in cortical neuron maturation and plasticity (Wagner et al., 2006).

Despite their structural and functional similarities, as well as their proximity to each other in space and time, there is little evidence for redundancy among RALDHs. Raldh2 null mice die at E9.5 due to failed development of many critical tissues, including the rostral CNS (Kumar et al., 2012), but Raldh3 expression in the anterior CNS and craniofacial regions is not different between control and Raldh2 null mice, indicating no compensatory increase in Raldh3. Loss of Raldh2 at E10.5 is sufficient to alter the migratory behavior, laminar position, and molecular identity of some cortical neurons (Haushalter et al., 2017), suggesting that, here again, RALDH3 does not 
compensate, despite its presence within the cortical layers (Smith et al., 2001).

An explanation for this lack of redundancy could be that each enzyme or combination of enzymes serves a unique purpose, such as providing protection from toxicity through rapid clearance of excess retinoids or producing RA for signaling. The diverse phenotypes found in mouse mutants of retinoid synthesis, degradation, and signaling components suggest that this is the case (Kam et al., 2012). Moreover, it has been hypothesized that the pool of RA generated by a given RALDH enzyme functions differently than that of another RALDH isozyme. A similar phenomenon involving enzymes regulating fatty acid metabolism has been observed in primary astrocyte cultures (Wakil and Abu-Elheiga, 2009; Napoli, 2012).

\section{RALDH2 is required for OPC production and differentiation}

Our results show that OLC numbers decrease following RALDH2 cKO. While controls displayed significant OPC population expansion between $\mathrm{P} 2$ and $\mathrm{P} 14$, the pool of OPCs in CKO mice did not grow over the same period, and OPC density was decreased by $>40 \%$ compared to controls. However, we found that these events were not attributable to impaired OPC proliferation or increased OLC death. Instead, they may be the result of insufficient generation of OPCs from the SVZ. This could be related to the increased death of Nestin ${ }^{+}$cells in the Raldh2 cKO SVZ, a finding that aligns with reports that RA is necessary for NSC survival (Crandall et al., 2004; Jacobs et al., 2006; Rajaii et al., 2008; Harrison-Uy et al., 2013; Mishra et al., 2016; Wu et al., 2016). The reduction in OPCs may also follow from reduced Gli1, indicative of decreased $\mathrm{SHH}$ signaling, in the subcallosal SVZ, where SHH is required for OPC production during early postnatal life (Tong et al., 2015; Sanchez and Armstrong, 2018; Winkler et al., 2018). In fact, it has been shown that loss of SHH signaling in postnatal Nestin ${ }^{+}$cells increased cell death in the SVZ, decreased SHH-dependent production of OPCs, and lead to a subsequent $30 \%$ reduction in callosal MBP expression (Machold et al., 2003).

$\mathrm{SHH}$ signaling is important for OPC specification in part because of its influence on Olig2, and there is evidence that RA is necessary for $\mathrm{SHH}$-dependent Olig2 expression either by directly enhancing Shh transcription via an upstream RARE or regulating SHH target gene expression, in particular that of Olig2 (Chang et al., 1997; Briscoe and Ericson, 1999; Ribes et al., 2006; Tan et al., 2006; Calder et al., 2015). A similar phenomenon may exist in dorsal forebrain OPC progenitors and may be disrupted by the loss of RALDH2.

Our findings also indicate that RALDH2 regulates the maturation of OPCs. cKO mice displayed a deficit in $\mathrm{CC}^{+}{ }^{+}$OLs relative to the total OLIG2 ${ }^{+}$population, suggesting that OPCs fail to differentiate. RA has been shown to regulate OPC maturation in vitro by favoring differentiation over continued proliferation, even in the presence of mitogens (Barres et al., 1994), suggesting that retinoids negatively regulate growth factor receptors such as PDGFR $\alpha$, which has been shown in other tissues (Balmer and Blomhoff, 2002; Reiterer et al., 2008; Okada et al., 2012). In the Raldh2 cKO mouse, therefore, it is possible that PDGF sensitivity persists in OPCs, thereby slowing differentiation.

In addition to a reduction in the number of $\mathrm{CC}_{1}{ }^{+} \mathrm{OLs}$, we observed decreased PLP signal in the CC of CKO mice between P14 and P120. This reduction is likely an effect of having too few OLs, but it may also reflect decreased P/p transcription. In C6 rat glioma cells, RA treatment upregulates Plp expression in a dose-dependent manner (Zhu et al., 1992). Moreover, in the neckless zebrafish mutant that lacks RALDH2, the expression of Mbp, another integral myelin protein, is reduced but can be rescued by exogenous RA (Kazakova et al., 2006). Despite the observed reduction in OLs and PLP, Raldh2 cKO mice displayed no obvious behavioral abnormalities within the first month of postnatal life. It is possible that the number of OLs in cKO mice, albeit reduced, was sufficient to maintain neuronal function during this time.

\section{RALDH2 is necessary for neuron and white matter astrocyte development}

We have shown that loss of RALDH2 decreases GFAP ${ }^{+}$ area in the postnatal CC, decreases the number of $\mathrm{CTIP}^{+}{ }^{+}$and $\mathrm{TBR}^{+}{ }^{+}$neurons in the layers 5 and 6 , and increases the number of SATB2 ${ }^{+}$neurons in upper layers. In conjunction with the decrease in OLIG2 ${ }^{+}$cells in the $\mathrm{CC}$, these results suggest that RALDH2 is involved in regulating the development of different cell types derived from NSCs in both embryonic and postnatal neurogenic and gliogenic structures (i.e., in the embryonic VZ and $S V Z$, the former of which is progressively lost during neurogenesis, and the postnatal SVZ) .

In Raldh2 cKO mice, we observed a reduction in $\mathrm{GFAP}^{+}$ area between P2 and P21, a time during which local astrocyte proliferation increases astrocyte numbers as much as 8 -fold, constituting $>50 \%$ of cortical astrocytes, and astrocytes undergo morphologic maturation, in part due to rising GFAP expression (Bandeira et al., 2009; Ge et al., 2012). RA alone or in synergy with ciliary neurotrophic factor (CNTF) is able to increase the number of $\mathrm{GFAP}^{+}$cells derived from late cortical progenitors in vitro, as well as increase Gfap expression (Faigle et al., 2008). RA synergizes with IL-6 family cytokines to relax chromatin around astrocyte genes and promote astrocytogenesis from NSCs (Asano et al., 2009; Herrera et al., 2010).

In addition to changes in OLC number and astrocyte development, we observed decreased numbers of $\mathrm{CTIP}^{+}{ }^{+}$and $\mathrm{TBR}^{+}$deep layer neurons and increased numbers of $\mathrm{SATB}^{+}{ }^{+}$neurons in the cortex of P2 Raldh2 cKO mice. This is consistent with previous accounts of RA perturbations disrupting neuronal development (Siegenthaler et al., 2009; Choi et al., 2014; Haushalter et al., 2017). Siegenthaler et al., (2009) studied cortical neurogenesis in the hypomorph-null hybrid Foxc1 mouse mutant, in which the dorsal forebrain meninges that strongly express RALDH2 fail to develop. Foxc1 mutants displayed a defect in the balance between symmetric (selfrenewing) and asymmetric (neurogenic) divisions, leading to a deficit in neurogenesis and decreased $\mathrm{CTIP}^{+}$and 
Table 1: Statistical summary

\begin{tabular}{|c|c|c|c|}
\hline Identifier & $\begin{array}{l}\text { Shapiro-Wilk } \\
\qquad(\alpha=0.05)\end{array}$ & Test & $95 \% \mathrm{Cl}$ \\
\hline a & Normal & Raldh2 mRNA puncta/mm; unpaired $t$ test between genotypes at $\mathrm{P} 2$, one-tailed & -2521 to -1732 \\
\hline b & Normal & PDGFR $\beta^{+}$structures $/ \mathrm{mm}^{2}$; unpaired $t$ test between genotypes at $\mathrm{P} 14$, two-tailed & -42.62 to 16.82 \\
\hline c & Normal & Laminin $^{+}$structures $/ \mathrm{mm}^{2}$; unpaired $t$ test between genotypes at $\mathrm{P} 14$, two-tailed & -94.79 to 21.25 \\
\hline d & Normal & ${\text { PDGFR } \beta^{+} \text {Laminin }^{+} / \text {Laminin }}^{+}$structures $\%$, unpaired $t$ test between genotypes at $\mathrm{P} 14$, two-tailed & -2.765 to 21.69 \\
\hline \multirow[t]{5}{*}{ e } & Normal & $\mathrm{OLIG}^{+}$cells $/ \mathrm{mm}^{2}$; one-way ANOVA with Sidak's test between genotypes at individual time points & \\
\hline & & $\mathrm{P} 2$ & 4.080 to 494.0 \\
\hline & & $\mathrm{P} 7$ & 80.47 to 547.6 \\
\hline & & P14 & 126.6 to 593.7 \\
\hline & & $\mathrm{P} 21$ & 108.9 to 681.0 \\
\hline f & Normal & OLIG2 $^{+}$cells $/ \mathrm{mm}^{2}$; unpaired $t$ test within control genotype between individual time points $\mathrm{P} 2$ vs $\mathrm{P} 21$, one-tailed & -441.0 to 282.2 \\
\hline g & Normal & OLIG2 ${ }^{+}$cells $/ \mathrm{mm}^{2}$; unpaired $t$ test within cKO genotype between individual time points $\mathrm{P} 2$ vs $\mathrm{P} 21$, one-tailed & -490.0 to 39.44 \\
\hline h & Normal & PDGFR $\alpha^{+} \mathrm{OLIG}^{+}$cells $/ \mathrm{mm}^{2}$; one-way ANOVA with Sidak's test for multiple comparisons between genotypes at individual time & points \\
\hline \multirow[t]{5}{*}{ i } & Normal & PDGFR $\alpha^{+} \mathrm{OLIG}^{+}$cells $/ \mathrm{mm}^{2}$; one-way ANOVA with Sidak's test for multiple comparisons within control genotype at individual & ime points \\
\hline & & P2 vs P7 & -121.2 to 55.21 \\
\hline & & $\mathrm{P} 7$ vs P14 & -184.2 to -16.61 \\
\hline & & $\mathrm{P} 14$ vs $\mathrm{P} 21$ & 8.089 to 221.1 \\
\hline & & $\mathrm{P} 2$ vs P21 & -224.6 to -42.19 \\
\hline \multirow[t]{5}{*}{ j } & Normal & $\begin{array}{l}\text { PDGFR } \alpha^{+} \mathrm{OLIG}^{+} / \mathrm{OLIG}^{+} \text {cells } / \mathrm{mm}^{2} \text {; one-way ANOVA with Sidak's test for multiple comparisons between genotypes at indivic } \\
\text { points }\end{array}$ & dual time \\
\hline & & $\mathrm{P} 2$ & -26.25 to -9.080 \\
\hline & & $\mathrm{P} 7$ & -21.13 to -3.288 \\
\hline & & $\mathrm{P} 14$ & -20.19 to -1.376 \\
\hline & & $\mathrm{P} 21$ & -12.09 to 6.720 \\
\hline \multirow[t]{4}{*}{$\mathrm{k}$} & Normal & $\mathrm{CC}_{1}{ }^{+} \mathrm{OLIG}^{+}{ }^{+}$cells $/ \mathrm{mm}^{2}$; one-way ANOVA with Sidak's test for multiple comparisons between genotypes at individual time poir & \\
\hline & & $\mathrm{P} 7$ & -21.38 to 87.30 \\
\hline & & $\mathrm{P} 14$ & 32.72 to 141.4 \\
\hline & & $\mathrm{P} 21$ & 49.38 to 158.1 \\
\hline \multirow[t]{3}{*}{ I } & Normal & $\begin{array}{l}\mathrm{CC} 1^{+} \mathrm{OLIG}_{2}^{+} \text {cells/OLIG2 }{ }^{+} \text {cells } \% \text {; one-way ANOVA with Sidak's test for multiple comparisons between genotypes at individu } \\
\text { points }\end{array}$ & al time \\
\hline & & P14 & 2.156 to 20.30 \\
\hline & & $\mathrm{P} 21$ & 1.024 to 19.16 \\
\hline \multirow[t]{5}{*}{$\mathrm{m}$} & Normal & $\mathrm{PLP}^{+}$area $\left(\mathrm{mm}^{2}\right)$; one-way ANOVA with Sidak's test for multiple comparisons between genotypes at individual time points & \\
\hline & & P7 & -18.20 to 107.8 \\
\hline & & $\mathrm{P} 14$ & 30.06 to 138.5 \\
\hline & & $\mathrm{P} 21$ & 25.44 to 139.2 \\
\hline & & $\mathrm{P} 120$ & 69.15 to 211.4 \\
\hline $\mathrm{n}$ & Normal & $\mathrm{TUNEL}^{+}$cells $/ \mathrm{mm}^{2}$; unpaired $t$ test within control genotype between individual time points $\mathrm{P} 2 \mathrm{vs} \mathrm{P} 7$, one-tailed & -41.86 to -15.94 \\
\hline o & Normal & TUNEL $^{+}$cells $/ \mathrm{mm}^{2}$; unpaired $t$ test within cKO genotype between individual time points $\mathrm{P} 2 \mathrm{vs} \mathrm{P} 7$, one-tailed & -18.13 to 4.871 \\
\hline \multirow[t]{4}{*}{$\mathrm{p}$} & Normal & TUNEL $^{+}$cells $/ \mathrm{mm}^{2}$; one-way ANOVA with Sidak's test for multiple comparisons between genotypes at individual time points & \\
\hline & & $\mathrm{P} 2$ & -9.109 to 16.03 \\
\hline & & P7 & -30.05 to -7.565 \\
\hline & & $\mathrm{P} 14$ & 0.9951 to 10.17 \\
\hline \multirow[t]{4}{*}{ q } & Normal & IBA1 ${ }^{+}$cells $/ \mathrm{mm}^{2}$ one-way ANOVA with Sidak's test for multiple comparisons between genotypes at individual time points & \\
\hline & & 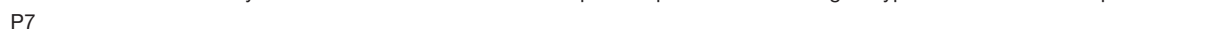 & -46.17 to 51.34 \\
\hline & & $\mathrm{P} 14$ & -92.57 to 4.941 \\
\hline & & P21 & -37.76 to 67.56 \\
\hline r & Normal & Gli1 mRNA puncta/mm²; unpaired $t$ test between genotypes at $\mathrm{P} 2$, one-tailed & $-15,405$ to -2876 \\
\hline s & Normal & Gli1 mRNA puncta/cell; $\mathrm{n}=$ number of cells, unpaired $t$ test between genotypes at $\mathrm{P} 2$, one-tailed & -3.692 to -1.703 \\
\hline $\mathrm{t}$ & Normal & $\mathrm{Gli1}^{+}$Olig2 ${ }^{+}$cells $/ \mathrm{mm}^{2} ;$ unpaired $t$ test between genotypes at $\mathrm{P} 2$, one-tailed & -53.01 to -33.57 \\
\hline \multirow[t]{5}{*}{ u } & Normal & ÄGFAP ${ }^{+}$area $\left(\mathrm{mm}^{2}\right)$; one-way ANOVA with Sidak's test for multiple comparisons between genotypes at individual time points & \\
\hline & & $\mathrm{P} 2$ & 0.8137 to 7.880 \\
\hline & & $\mathrm{P} 7$ & 4.695 to 12.44 \\
\hline & & P14 & 6.558 to 14.30 \\
\hline & & $\mathrm{P} 21$ & 3.638 to 11.38 \\
\hline$v$ & Normal & SATB2 $^{+}$cells $/ \mathrm{mm}^{2}$; unpaired $t$ test between genotypes at $\mathrm{P} 2$, one-tailed & 159.9 to 1991 \\
\hline w & Normal & CTIP2 ${ }^{+}$cells $/ \mathrm{mm}^{2}$; unpaired $t$ test between genotypes at $\mathrm{P} 2$, two-tailed & -172.6 to -68.02 \\
\hline $\mathrm{x}$ & Normal & $\mathrm{TBR}^{+}{ }^{+}$cells $/ \mathrm{mm}^{2} ;$ unpaired $t$ test between genotypes at $\mathrm{P} 2$, two-tailed & -1407 to -439.5 \\
\hline y & Normal & Cortical thickness (um); unpaired $t$ test between genotypes at $\mathrm{P} 2$, two-tailed & -234.6 to 26.12 \\
\hline
\end{tabular}

$\mathrm{TBR}^{+}$neurons. This could be partially rescued by exogenous RA and suggests that endogenous RALDH2 influences neurogenesis. In a different model of RALDH2 lossof-function later in embryogenesis, early postmitotic neurons left the intermediate zone (IZ, the anlage of the $\mathrm{CC}$ ) too rapidly and settled in the deep layers, leading to a surplus of deep layer neurons and a deficit in upper layer neurons [this study used a cytomegalovirus (CMV)- $\beta$-actin -Cre ${ }^{E R T 2}:$ Raldh2 $2^{\text {flox/flox }}$ mouse line and Tamoxifen was ad- ministered at E10; Haushalter et al., 2017], suggesting that RA signaling occurs in postmitotic migratory neurons to regulate migration and molecular identity. Furthermore, it has been shown that when a dominant negative RAR (dnRAR403) is introduced in the developing cortical plate during neurogenesis, neuroblasts only transiently express their appropriate cell markers before adopting neuronal identities from other layers and migrating to the layer corresponding to the new identity (Choi et al., 2014). A 
similar phenomenon may occur in the Raldh2 cKO, such that deep layer neurons lose their layer 5 and 6 identities and take on those of the upper layers. Overall, our findings suggest that RA may play multiple roles in neuronal development, as well as in glial development and myelination.

\section{References}

Asano $\mathrm{H}$, Aonuma M, Sanosaka T, Kohyama J, Namihira M, Nakashima K (2009) Astrocyte differentiation of neural precursor cells is enhanced by retinoic acid through a change in epigenetic modification. Stem Cells Dayt Ohio 27:2744-2752.

Asson-Batres MA, Smith WB (2006) Localization of retinaldehyde dehydrogenases and retinoid binding proteins to sustentacular cells, glia, Bowman's gland cells, and stroma: potential sites of retinoic acid synthesis in the postnatal rat olfactory organ. J Comp Neurol 496:149-171.

Asson-Batres MA, Zeng M-S, Savchenko V, Aderoju A, McKanna J (2003) Vitamin A deficiency leads to increased cell proliferation in olfactory epithelium of mature rats. J Neurobiol 54:539-554.

Balmer JE, Blomhoff R (2002) Gene expression regulation by retinoic acid. J Lipid Res 43:1773-1808.

Bandeira F, Lent R, Herculano-Houzel S (2009) Changing numbers of neuronal and non-neuronal cells underlie postnatal brain growth in the rat. Proc Natl Acad Sci USA 106:14108-14113.

Barres BA, Lazar MA, Raff MC (1994) A novel role for thyroid hormone, glucocorticoids and retinoic acid in timing oligodendrocyte. Development 120:1097-1108.

Bhat PV, Rao PB (1978) Vitamin A nutrition in relation to gangliosides and myelination in the developing brain. World Rev Nutr Diet 31:100-106.

Briscoe J, Ericson J (1999) The specification of neuronal identity by graded Sonic Hedgehog signalling. Semin Cell Dev Biol 10:353362.

Calder EL, Tchieu J, Steinbeck JA, Tu E, Keros S, Ying S-W, Jaiswal MK, Cornacchia D, Goldstein PA, Tabar V, Studer L (2015) Retinoic acid-mediated regulation of GLI3 enables efficient motoneuron derivation from human ESCs in the absence of extrinsic $\mathrm{SHH}$ activation. J Neurosci 35:11462-11481.

Chang BE, Blader P, Fischer N, Ingham PW, Strähle U (1997) Axial (HNF3beta) and retinoic acid receptors are regulators of the zebrafish sonic hedgehog promoter. EMBO J 16:3955-3964.

Chang JT, Lehtinen MK, Sive H (2016) Zebrafish cerebrospinal fluid mediates cell survival through a retinoid signaling pathway. Dev Neurobiol 76:75-92.

Choi J, Park S, Sockanathan S (2014) Activated retinoid receptors are required for the migration and fate maintenance of subsets of cortical neurons. Development 141:1151-1160.

Clausen J (1969) The effect of vitamin A deficiency on myelination in the central nervous system of the rat. Eur J Biochem 7:575-582.

Crandall J, Sakai Y, Zhang J, Koul O, Mineur Y, Crusio WE, McCaffery $P$ (2004) 13-cis-retinoic acid suppresses hippocampal cell division and hippocampal-dependent learning in mice. Proc Natl Acad Sci USA 101:5111-5116.

Dai J, Bercury KK, Ahrendsen JT, Macklin WB (2015) Olig1 function is required for oligodendrocyte differentiation in the mouse brain. $J$ Neurosci 35:4386-4402.

Dheen ST, Jun Y, Yan Z, Tay SSW, Ling EA (2005) Retinoic acid inhibits expression of TNF- $\alpha$ and iNOS in activated rat microglia. Glia 50:21-31.

Emery B (2010) Regulation of oligodendrocyte differentiation and myelination. Science 330:779-782.

Faigle R, Liu L, Cundiff P, Funa K, Xia Z (2008) Opposing effects of retinoid signaling on astrogliogenesis in embryonic day 13 and 17 cortical progenitor cells. J Neurochem 106:1681-1698.

Foran DR, Peterson AC (1992) Myelin acquisition in the central nervous system of the mouse revealed by an MBP-Lac $Z$ transgene. J Neurosci 12:4890-4897.
Ge WP, Miyawaki A, Gage FH, Jan YN, Jan LY (2012) Local generation of glia is a major astrocyte source in postnatal cortex. Nature 484:376-380.

Goncalves MB, Wu Y, Trigo D, Clarke E, Malmqvist T, Grist J, Hobbs C, Carlstedt TP, Corcoran JPT (2018) Retinoic acid synthesis by NG2 expressing cells promotes a permissive environment for axonal outgrowth. Neurobiol Dis 111:70-79.

Goncalves MB, Wu Y, Clarke E, Grist J, Hobbs C, Trigo D, Jack J, Corcoran JPT (2019) Regulation of myelination by exosome associated retinoic acid release from NG2-positive cells. J Neurosci 36:3013-3027.

Gudas LJ (2012) Emerging roles for retinoids in regeneration and differentiation in normal and disease states. Biochim Biophys Acta 1821:213-221.

Hägglund M, Berghard A, Strotmann J, Bohm S (2006) Retinoic acid receptor-dependent survival of olfactory sensory neurons in postnatal and adult mice. J Neurosci 26:3281-3291.

Harrison-Uy SJ, Siegenthaler JA, Faedo A, Rubenstein JLR, Pleasure SJ (2013) CoupTFI interacts with retinoic acid signaling during cortical development. PLoS One 8:e58219.

Haushalter C, Schuhbaur B, Dollé P, Rhinn M (2017) Meningeal retinoic acid contributes to neocortical lamination and radial migration during mouse brain development. Biol Open 6:148-160.

Herculano-Houzel S, Mota B, Lent R (2006) Cellular scaling rules for rodent brains. Proc Natl Acad Sci USA 103:12138-12143.

Herrera F, Chen Q, Schubert D (2010) Synergistic effect of retinoic acid and cytokines on the regulation of glial fibrillary acidic protein expression. J Biol Chem 285:38915-38922.

Huang JK, Jarjour AA, Oumesmar BN, Kerninon C, Williams A, Krezel W, Kagechika H, Bauer J, Zhao C, Evercooren A-V, Chambon P, Ffrench-Constant C, Franklin RJM (2011) Retinoid X receptor gamma signaling accelerates CNS remyelination. Nat Neurosci 14:45-53.

Jacobs S, Lie DC, DeCicco KL, Shi Y, DeLuca LM, Gage FH, Evans RM (2006) Retinoic acid is required early during adult neurogenesis in the dentate gyrus. Proc Natl Acad Sci USA 103:3902-3907.

Kam RKT, Deng Y, Chen Y, Zhao H (2012) Retinoic acid synthesis and functions in early embryonic development. Cell Biosci 2:11.

Kazakova N, Li H, Mora A, Jessen KR, Mirsky R, Richardson WD, Smith HK (2006) A screen for mutations in zebrafish that affect myelin gene expression in Schwann cells and oligodendrocytes. Dev Biol 297:1-13.

Kean EL (1970) Vitamin A deficiency and glycolipid sulfation. J Lipid Res 11:248-258.

Kelly KK, MacPherson AM, Grewal H, Strnad F, Jones JW, Yu J, Pierzchalski K, Kane MA, Herson PS, Siegenthaler JA (2016) Col1a1 + perivascular cells in the brain are a source of retinoic acid following stroke. BMC Neurosci 17:49.

Kern J, Schrage K, Koopmans GC, Joosten EA, McCaffery P, Mey J (2007) Characterization of retinaldehyde dehydrogenase-2 induction in NG2-positive glia after spinal cord contusion injury. Int $J$ Dev Neurosci 25:7-16.

Kumar S, Sandell LL, Trainor PA, Koentgen F, Duester G (2012) Alcohol and aldehyde dehydrogenases: retinoid metabolic effects in mouse knockout models. Biochim Biophys Acta 1821:198-205.

Laeng P, Décimo D, Pettmann B, Janet T, Labourdette G (1994) Retinoic acid regulates the development of oligodendrocyte precursor cells in vitro. J Neurosci Res 39:613-633.

Lang J, Maeda Y, Bannerman P, Xu J, Horiuchi M, Pleasure D, Guo F (2013) Adenomatous polyposis coli regulates oligodendroglial development. J Neurosci 33:3113-3130.

Machold R, Hayashi S, Rutlin M, Muzumdar MD, Nery S, Corbin JG, Gritli-Linde A, Dellovade T, Porter JA, Rubin LL, Dudek H, McMahon AP, Fishell G (2003) Sonic hedgehog is required for progenitor cell maintenance in telencephalic stem cell niches. Neuron 39: 937-950.

Maden M (2002) Retinoid signalling in the development of the central nervous system. Nat Rev Neurosci 3:843-853.

Marques S, Zeisel A, Codeluppi S, van Bruggen D, Mendanha Falcão A, Xiao L, Li H, Häring M, Hochgerner H, Romanov RA, Gyllborg D, 
Muñoz Manchado A, La Manno G, Lönnerberg P, Floriddia EM, Rezayee F, Ernfors P, Arenas E, Hjerling-Leffler J, Harkany T, et al. (2016) Oligodendrocyte heterogeneity in the mouse juvenile and adult central nervous system. Science 352:1326-1329.

Marques S, van Bruggen D, Vanichkina DP, Floriddia EM, Munguba H, Väremo L, Giacomello S, Falcão AM, Meijer M, Björklund ÅK, Hjerling-Leffler J, Taft RJ, Castelo-Branco G (2018) Transcriptional convergence of oligodendrocyte lineage progenitors during development. Dev Cell 46:504-517.e7.

Mey J, J Morassutti D, Brook G, Liu R-H, Zhang YP, Koopmans G, McCaffery P (2005) Retinoic acid synthesis by a population of NG2-positive cells in the injured spinal cord. Eur J Neurosci 21: 1555-1568.

Mishra S, Choe Y, Pleasure SJ, Siegenthaler JA (2016) Cerebrovascular defects in Foxc1 mutants correlate with aberrant WNT and VEGF-a pathways downstream of retinoic acid from the meninges. Dev Biol 420:148-165.

Napoli JL (2012) Physiological insights into all-trans-retinoic acid biosynthesis. Biochim Biophys Acta 1821:152-167.

Nave KA (2010) Myelination and support of axonal integrity by glia. Nature 468:244-252.

Niederreither K, McCaffery P, Dräger UC, Chambon P, Dollé P (1997) Restricted expression and retinoic acid-induced downregulation of the retinaldehyde dehydrogenase type 2 (RALDH-2) gene during mouse development. Mech Dev 62:67-78.

Noll E, Miller RH (1994) Regulation of oligodendrocyte differentiation: a role for retinoic acid in the spinal cord. Development 120:649660.

Norlin EM, Alenius M, Gussing F, Hägglund M, Vedin V, Bohm S (2001) Evidence for gradients of gene expression correlating with zonal topography of the olfactory sensory map. Mol Cell Neurosci 18:283-295.

Okada H, Honda M, Campbell JS, Sakai Y, Yamashita T, Takebuchi Y, Hada K, Shirasaki T, Takabatake R, Nakamura M, Sunagozaka H, Tanaka T, Fausto N, Kaneko S (2012) Acyclic retinoid targets platelet-derived growth factor signaling in the prevention of hepatic fibrosis and hepatocellular carcinoma development. Cancer Res 72:4459-4471.

Paschaki M, Schneider C, Rhinn M, Thibault-Carpentier C, Dembélé D, Niederreither K, Dollé P (2013) Transcriptomic analysis of murine embryos lacking endogenous retinoic acid signaling. PLoS One 8:e62274

Rajaii F, Bitzer ZT, Xu Q, Sockanathan S (2008) Expression of the dominant negative retinoid receptor, RAR403, alters telencephalic progenitor proliferation, survival, and cell fate specification. Dev Biol 316:371-382.

Reiterer G, Bunaciu RP, Smith JL, Yen A (2008) Inhibiting the platelet derived growth factor receptor increases signs of retinoic acid syndrome in myeloid differentiated HL-60 cells. FEBS Lett 582: $2508-2514$

Ribes V, Wang Z, Dollé P, Niederreither K (2006) Retinaldehyde dehydrogenase 2 (RALDH2)-mediated retinoic acid synthesis regulates early mouse embryonic forebrain development by controlling FGF and sonic hedgehog signaling. Development 133:351361.

Richardson WD, Kessaris N, Pringle N (2006) Oligodendrocyte wars. Nat Rev Neurosci 7:11-18.

Saab AS, Tzvetanova ID, Nave K-A (2013) The role of myelin and oligodendrocytes in axonal energy metabolism. Curr Opin Neurobiol 23:1065-1072.

Sanchez MA, Armstrong RC (2018) Postnatal Sonic hedgehog (Shh) responsive cells give rise to oligodendrocyte lineage cells during myelination and in adulthood contribute to remyelination. Exp Neurol 299:122-136.

Siegenthaler JA, Ashique AM, Zarbalis K, Patterson KP, Hecht JH, Kane MA, Folias AE, Choe Y, May SR, Kume T, Napoli JL, Peterson AS, Pleasure SJ (2009) Retinoic acid from the meninges regulates cortical neuron generation. Cell 139:597-609.
Smith D, Wagner E, Koul O, McCaffery P, Dräger UC (2001) Retinoic acid synthesis for the developing telencephalon. Cereb Cortex 11:894-905.

Stangel M (2012) Neurodegeneration and neuroprotection in multiple sclerosis. Curr Pharm Des 18:4471-4474.

Steenweg ME, Vanderver A, Blaser S, Bizzi A, de Koning TJ, Mancini GMS, van Wieringen WN, Barkhof $\mathrm{F}$, Wolf NI, van der Knaap MS (2010) Magnetic resonance imaging pattern recognition in hypomyelinating disorders. Brain 133:2971-2982.

Takamura R, Watamura N, Nikkuni M, Ohshima T (2017) All-trans retinoic acid improved impaired proliferation of neural stem cells and suppressed microglial activation in the hippocampus in an Alzheimer's mouse model. J Neurosci Res 95:897-906.

Tan M, Hu X, Qi Y, Park J, Cai J, Qiu M (2006) Gli3 mutation rescues the generation, but not the differentiation, of oligodendrocytes in Shh mutants. Brain Res 1067:158-163.

Tong CK, Fuentealba LC, Shah JK, Lindquist RA, Ihrie RA, Guinto CD, Rodas-Rodriguez JL, Alvarez-Buylla A (2015) A dorsal SHHdependent domain in the V-SVZ produces large numbers of oligodendroglial lineage cells in the postnatal brain. Stem Cell Rep 5:461-470.

Traiffort E, Zakaria M, Laouarem Y, Ferent J (2016) Hedgehog: a key signaling in the development of the oligodendrocyte lineage. J Dev Biol 4:28.

Vanlandewijck M, He L, Mäe MA, Andrae J, Ando K, Del Gaudio F, Nahar K, Lebouvier T, Laviña B, Gouveia L, Sun Y, Raschperger E, Räsänen M, Zarb Y, Mochizuki N, Keller A, Lendahl U, Betsholtz C (2018) A molecular atlas of cell types and zonation in the brain vasculature. Nature 554:475-480.

Vermot J, Garnier J-M, Dierich A, Niederreither K, Harvey RP, Chambon P, Dollé P (2006) Conditional (loxP-flanked) allele for the gene encoding the retinoic acid-synthesizing enzyme retinaldehyde dehydrogenase 2 (RALDH2). Genes 44:155-158.

Wagner E, Luo T, Dräger UC (2002) Retinoic acid synthesis in the postnatal mouse brain marks distinct developmental stages and functional systems. Cereb Cortex 12:1244-1253.

Wagner E, Luo T, Sakai Y, Parada LF, Dräger UC (2006) Retinoic acid delineates the topography of neuronal plasticity in postnatal cerebral cortex. Eur J Neurosci 24:329-340.

Wakil SJ, Abu-Elheiga LA (2009) Fatty acid metabolism: target for metabolic syndrome. J Lipid Res 50:S138-S143.

Wilkins A, Majed H, Layfield R, Compston A, Chandran S (2003) Oligodendrocytes promote neuronal survival and axonal length by distinct intracellular mechanisms: a novel role for oligodendrocytederived glial cell line-derived neurotrophic factor. J Neurosci 23: 4967-4974.

Winkler CC, Yabut OR, Fregoso SP, Gomez HG, Dwyer BE, Pleasure SJ, Franco SJ (2018) The dorsal wave of neocortical oligodendrogenesis begins embryonically and requires multiple sources of sonic hedgehog. J Neurosci 38:5237-5250.

Wu CY, Persaud SD, Wei L-N (2016) Retinoic acid induces ubiquitination-resistant RIP140/LSD1 complex to fine-tune Pax6 gene in neuronal differentiation. Stem Cells 34:114-123.

Yamamoto M, McCaffery P, Dräger UC (1996) Influence of the choroid plexus on cerebellar development: analysis of retinoic acid synthesis. Brain Res Dev Brain Res 93:182-190.

Zhou Q, Anderson DJ (2002) The bHLH transcription factors OLIG2 and OLIG1 couple neuronal and glial subtype specification. Cell 109:61-73.

Zhou Q, Wang S, Anderson DJ (2000) Identification of a novel family of oligodendrocyte lineage-specific basic helix-loop-helix transcription factors. Neuron 25:331-343.

Zhu W, Kanoh M, Ye P, Laszkiewicz I, Royland JE, Wiggins RC, Konat G (1992) Retinoic acid-regulated expression of proteolipid protein and myelin-associated glycoprotein genes in C6 glioma cells. J Neurosci Res 31:745-750.

Zhu X, Bergles DE, Nishiyama A (2008) NG2 cells generate both oligodendrocytes and gray matter astrocytes. Development 135: 145-157. 